\title{
Actions that protect: Promoting sexual and reproductive health and choice among young people in India
}

Shireen J. Jejeebhoy

Population Council

Mary Philip Sebastian

Population Council

Follow this and additional works at: https://knowledgecommons.popcouncil.org/departments_sbsr-rh

Part of the Demography, Population, and Ecology Commons, Family, Life Course, and Society Commons, and the International Public Health Commons How does access to this work benefit you? Let us know!

\section{Recommended Citation}

Jejeebhoy, Shireen J. and Mary Philip Sebastian. 2003. "Actions that protect: Promoting sexual and reproductive health and choice among young people in India," South \& East Asia Regional Working Paper no. 18. New Delhi: Population Council. 


\section{South \& East Asia}

Actions that protect: Promoting sexual and reproductive health and choice among young people in India

Shireen J Jejeebhoy

Mary Philip Sebastian 


\section{Actions that protect: Promoting sexual and reproductive health and choice among young people in India}

Shireen J Jejeebhoy

Mary Philip Sebastian

Population Council, New Delhi, India 



\section{Contents}

List of tables and figures

Abstract $\quad$ V

Acknowledgements vi

Caveat vi

1. Introduction 1

2. Context of sexual relations among young people 2

Onset of sexual relations within marriage 3

Premarital sexual relations 3

Sexual relations: How risky? 5

$\begin{array}{ll}\text { Associated risk behaviours } & 9\end{array}$

3. Reproductive health outcomes 10

$\begin{array}{ll}\text { Pregnancy and childbearing } & 10\end{array}$

Reproductive tract and sexually transmitted infections, $\quad 11$ including HIV/AIDS

4. Underlying risk and protective behaviours 13

Raising awareness and overcoming misperceptions 13

Building self-efficacy, negotiation, life and livelihood skills $\quad 17$

Strengthening linkages with parents: Communication, 23

interaction and support on sexual and

reproductive health matters

Making programmes youth-centred and youth-led 25

5. Changing policy and programme environment 29

6. Conclusions and recommendations 33

$\begin{array}{lr}\text { References } & 40\end{array}$

$\begin{array}{ll}\text { Appendices } & 48\end{array}$ 


\section{List of tables and figures}

Table 1: Percentage of young women married by age 13,15,18 years 3

Table 2: Frequency of condom use among sexually experienced 7 male students by type of partner, Mumbai: \% distribution

Figure 1: Premarital sexual activity among youth: Selected studies, 1990s 4

Figure 2: Percentage of adolescent females and males (16-17 years) 9 in Goa reporting non-consensual sexual experiences

Figure 3: Intervention participants and non-participants reporting 22 selected reproductive health behaviours $(\%)$

\section{Appendix tables}

Table 1: Age at marriage among adolescents, India, 1998-99 49

Table 2: Casual sex experience among adolescents aged 15-19, India, $2001 \quad 50$

Table 3: Contraceptive use and unmet need for contraception 51 among married adolescents aged 15-19

Table 4: Unsafe pregnancy outcomes among adolescents: 52 Risk factors and neonatal mortality rates

Table 5: In-depth awareness of HIV-related issues: \% adolescents aged 15-19 aware of important methods of HIV prevention and correctly aware of three common misconceptions on transmission of HIV/AIDS

Table 6: Pregnancy-related care among adolescents aged 15-19 


\section{Abstract}

This paper synthesises the evidence on the sexual and reproductive health situation of young people in India, and explores what we know about underlying factors that place them at risk of or protect them from unsafe and unwanted sexual and reproductive health experiences. The picture that emerges suggests that substantial proportions of young people experience risky or unwanted sexual activity, do not receive prompt or appropriate care, and experience adverse reproductive health outcomes. Contextual factors such as poverty, gender imbalances and lack of education or livelihood opportunities clearly increase the vulnerability of youth. Other factors at the family, community and facility level may also exacerbate risk. While young people's knowledge and awareness about sexual and reproductive health is increasing, much of this knowledge remains superficial and ridden with myths, misperceptions and a sense of invulnerability. Gender power imbalances make risky behaviours acceptable, encourage secrecy and fear of disclosure, and inhibit negotiation among partners. Lack of communication with parents and other trusted adults, similarly, keeps young people ill informed and unlikely to receive parental support or counsel in relation to sexual matters. Sexuality education remains inadequate and irrelevant to young people's needs, and services remain inaccessible, unacceptable, unaffordable and of indifferent quality. Several encouraging signs are, however, evident. The sexual and reproductive health needs of adolescents and young people are on the national agenda. There is growing recognition that young people themselves must be given a role in articulating, designing, implementing and evaluating such programmes. Finally, experiences of a few programmes already exist that appear to successfully respond to young people's sexual and reproductive health needs in innovative and acceptable ways. The paper concludes by recommending, on the basis of available evidence, a core set of promising actions that protect. 


\section{Acknowledgements}

We are grateful to Leena Abraham, Dinesh Agarwal, Deepika Ganju, Veera Mendonca, Vijaya Nidadavolu, K.G. Santhya, Komal Saxena and Anjali Widge for their valuable suggestions and comments. Support from the MacArthur Foundation and WHO South and East Asia Regional Office is acknowledged.

\section{Caveat}

Information is in a state of fluidity. Since writing the original draft of this paper, new information and data have been published and have expanded what we know about the sexual and reproductive health situation of young people in India. As far as possible we have tried to update the paper, but we recognise that there will always be gaps, and perhaps whole areas of importance that we have failed to address. We would be grateful for any further relevant information and will try to incorporate it into our next publication. 


\section{Introduction}

There are an estimated 300 million young people (aged 10-24) - that is, adolescents (aged 10-19) and youth (aged 15-24) — in India today representing almost one-third (31 per cent) of the population. Specifically, 22 per cent of the population falls into the adolescent age group (aged 10-19) (IIPS and ORC Macro 2000; United Nations 2001).

Young people in India are healthier, more urbanised and better educated than earlier generations; they experience puberty at younger ages, and marry and have children later than in the past. At the same time, they face significant risks related to sexual and reproductive health, and many lack the power to make informed sexual and reproductive choices. These vulnerabilities remain poorly understood and served, and it is only over the last decade that researchers and policy makers have begun to shed their traditional ambivalence to these issues. Even so, there is little evidence that identifies the factors that protect young people's ability to ensure safe sexual and reproductive health and their autonomy to make informed and wanted decisions.

The objective of this paper is to focus on what we know about underlying factors that place young people in India at risk of or protect them from unsafe and unwanted sexual and reproductive health experiences. We start with a brief overview of the sexual and reproductive health situation of young people, then present the evidence available — albeit slim and unrepresentative — on underlying factors, and finally make recommendations — some tentative and speculative — on actions that may protect young people.

Although what is presented refers to young people in general terms, the available evidence cautions that young people's situation varies tremendously by age, sex, marital status, class, region and cultural context, and correspondingly calls for interventions that are flexible and responsive to these disparate needs. 


\section{Context of sexual relations among young people}

A brief look at the socio-demographic profile of young people suggests that:

- A significant proportion of young people remain illiterate and wide geographic disparities in school attendance - particularly middle and secondary school enrolment - persist. For example, among adolescents aged 15-17, 63 per cent of those living in urban areas attend school, compared to 44 per cent of those in rural areas. As is well-known, school attendance varies widely by state - while over 90 per cent of those aged 6-17 were in school in such states as Himachal Pradesh and Kerala, only 60 per cent were in school in Bihar (IIPS and ORC Macro 2000).

- Gender disparities are also stark. While 15 per cent of young males aged 15-19 are illiterate, about twice this percentage ( 32 per cent) of females are illiterate. And while 58 per cent of young males in the eligible ages are enrolled in middle and secondary school, only 40 per cent of young females are (IIPS and ORC Macro 2000). Even so, the proportion of women aged 20-29 who report seven or more years of education (34 per cent) is dramatically higher than the proportion of older women aged 40-49 who do so (17 per cent) (IIPS and ORC Macro 2000).

- A substantial proportion of young people are economically active. By ages 15-19, large proportions of young boys (44 per cent) and girls ( 26 per cent) are engaged in economic activity; however these figures may not adequately reflect girls' contributions to household labour. Rural adolescents are more likely to work and less likely to study than their urban counterparts (ILO 1998).

- Mortality rates among young people are generally lower than those observed at younger and older ages, a reflection of the fact that youth is a generally healthy period of life. However, gender disparities are apparent, particularly among young people aged 15-19 (2.5 and 1.8, respectively per 1,000 females and males) and 20-24 (3.8 and 2.7 per 1,000 respectively), and may be explained by the poorer reproductive health of young women at these ages (IIPS and ORC Macro 2000). 


\section{Onset of sexual relations within marriage}

While international attention tends to focus on premarital sexual activity among young people, for young women in India, sexual relations occur overwhelmingly within the context of marriage (see Pelto, Joshi and Verma 2000). Despite the rising age at marriage and laws prohibiting early marriage (Child Marriage Restraint Act of 1929 and its amendment in 1978), half of all women aged 20-24 were married by 18 years and a quarter by 15 years (see Table 1; IIPS and ORC Macro 2000; Santhya and Jejeebhoy 2003). Among females aged 15-19 at the time of the survey, one-third were already married. In contrast, boys rarely marry in adolescence - only 6 per cent of those aged 15-19 were married at the time of the survey (IIPS and ORC Macro 2000; Kulkarni 2003).

\section{Table 1: Percentage of young women married by age 13, 15, 18 years}

\begin{tabular}{|l|r|c|}
\hline \multirow{2}{*}{} & \multicolumn{2}{|c|}{ Women currently aged } \\
\cline { 2 - 3 } & $\mathbf{2 0 - 2 4}$ & $\mathbf{2 5 - 2 9}$ \\
\hline Percentage ever married & 78.8 & 94.5 \\
Percentage married by age 13 & 8.9 & 12.1 \\
Percentage married by age 15 & 23.5 & 29.2 \\
Percentage married by age 18 & 50.0 & 58.9 \\
Percentage married in adolescence (by age 20) & 67.1 & 74.9 \\
\hline
\end{tabular}

Source: IIPS and ORC Macro 2000

There is considerable state-wise variation in age at marriage (see Appendix Table 1). Early marriage is concentrated in the large northern states of Bihar (and Jharkhand), Madhya Pradesh (and Chhattisgarh), Rajasthan and Uttar Pradesh (and Uttaranchal). In these states, and in Andhra Pradesh in the south, over 40 per cent of all girls aged 15-19 are already married; moreover, 40 per cent or more women aged $20-24$ were already married by age 15 . While marriage among males takes place far more rarely in adolescence, it is these same states excluding Andhra Pradesh in which between 10 per cent and 21 per cent of those aged 15-19 are already married (IIPS and ORC Macro 2000).

\section{Premarital sexual relations}

While marriage marks the onset of sexual activity among the large majority of young females, there is growing evidence of premarital onset of sexual activity, particularly among young males. Evidence comes from small case studies, usually among urban rather than rural youth, from schools and universities rather than communities more generally and, as a result, findings are usually unrepresentative of the general population. While it is difficult to generalise, studies suggest a 
consistent picture (see Figure 1). Premarital sexual activity is clearly more common among men than women, although some difference may reflect over-reporting among males and under-reporting among females. Typically, fewer than 10 per cent of young women reported premarital sexual experience, while a higher range (15-30 per cent) was observed among young males (see for example, Abraham and Kumar 1999; Awasthi, Nichter and Pande 2000; Bang et al. 1989; Bansal 1992; Bhende 1995; Goparaju 1993; IMRB 1993; Jejeebhoy 2000; Kaur et al. 1996; Mehra, Savithri and Coutinho 2002a; Savara and Sridhar 1993; 1994; Sehgal, Sharma and Bhattacharya 1992; Sharma and Sharma 1995; Watsa 1993). Evidence also suggests that among young females and males who are sexually active before marriage, age at sexual debut occurs in late adolescence (Abraham and Kumar 1999; Goparaju 1993; Savara and Sridhar 1993; 1994; Sharma and Sharma 1995). Finally, there is some evidence to suggest that several more anticipate sexual activity and sexual debut in the foreseeable future: for example, while 15-17 per cent of young males in a Lucknow slum reported sexual activity, some 38 per cent reported anticipating a sexual encounter in the next six months (Awasthi, Nichter and Pande 2000).

\section{Figure 1: Premarital sexual activity among youth: Selected studies, 1990s}

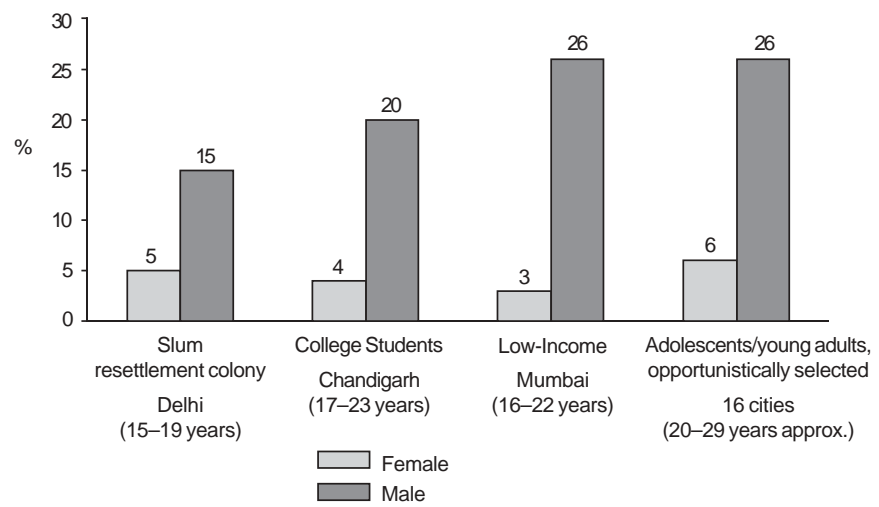

Source: Mehra, Savithri and Coutinho 2002 (Delhi); Kaur et al. 1996 (Chandigarh); Abraham and Kumar 1999 (Mumbai); Watsa 1993 (16-city study).

Studies suggest that sexual behaviour falls along a continuum: from non-penetrative activities such as handholding, kissing and touching to intercourse. For example, a study of low-income college students in Mumbai shows that while 26 per cent of young men and 3 per cent of young women reported penetrative sex, many more - 49 per cent and 13 per cent, respectively reported other forms of physical intimacy such as kissing and touching (Abraham and Kumar 1999). The suggestion that penetrative sexual activity may be preceded by periods of non-penetrative experience offers a window of opportunity for counselling and safe sex messages. 


\section{Sexual relations: How risky?}

\section{Multiple partners and casual sexual relations}

Evidence indicates that the nature of premarital partnerships differs significantly between men and women. The majority of sexually experienced unmarried women report having sex with a steady partner with marriage in mind (Brown et al. 2001). In contrast, sexually active young males in several qualitative and quantitative studies have reported engaging in sex with multiple partners, casual partners and commercial sex workers. While there is wide variation in reported casual relations, between 20 per cent and 40 per cent of sexually active boys report a causal sexual experience (see for example Abraham and Kumar 1999; Goparaju 1993; Jejeebhoy 2000; NACO and UNICEF 2002; Savara and Sridhar 1993; Sharma and Sharma 1995). Indeed, in a study of low-income college-going youth in Mumbai, boys distinguished between "true love" and "time-pass" partners, the latter signifying a familiarity with casual sexual relations (Abraham 2003). Several studies indicate that young men report a range of partners in addition to sex workers; these include "bhabhis" and "aunties," that is, older married women in the neighbourhood (Abraham and Kumar 1999; Goparaju 1993; Jejeebhoy 2000; Pelto 1999; Sehgal, Sharma and Bhattacharya 1992).

According to the recent report on knowledge, attitudes and practice of youth drawn from the National AIDS Control Organisation (NACO) National Behavioural Surveillance Survey, some 10 per cent and 8 per cent of rural and urban young men aged 15-19, respectively, reported a casual sex encounter in the 12 months preceding the survey compared to 2 per cent of sexually active young rural and urban females (NACO and UNICEF 2002). Furthermore, age appears to be associated with increased casual sex experiences, particularly among young males; for females, there is no corresponding variation. For example, among urban males, the percentage reporting casual sex in a one-year recall increased from 8 per cent among those aged 15-19 to 13 per cent among those aged 20-24; rural males correspondingly reported an increase from 10 per cent to 15 per cent. There is, however, considerable state-wise variation in casual sex experiences. States with particularly high proportions of adolescent males (15 per cent or more) reporting casual experiences include Andhra Pradesh in the south, Bihar and Madhya Pradesh in the north, Gujarat in the west, and Arunachal Pradesh, Mizoram and Sikkim in the north-east. Those with particularly high proportions of young females (5 per cent or more) reporting a casual experience include Andhra Pradesh and Kerala in the south, Bihar in the north, Maharashtra in the west, and Arunachal Pradesh and Nagaland in the north-east (see Appendix Table 2). In summary, there does not appear to be a regional concentration in the percentage of adolescents reporting high levels of causal sexual relations. 
Smaller studies suggest that the prevalence of casual sexual relations may be more widespread. For example, roughly one in four or five sexually active young males reported a casual sexual encounter in studies of young people drawn from 16 cities (19 per cent; Watsa 1993), the slums of Lucknow (19 per cent; Awasthi, Nichter and Pande 2000) and a college setting in Hyderabad (25 per cent; Goparaju 1993). Higher rates are reported in a recent study of adolescents in a low-income setting in Delhi in which one-third of sexually experienced boys aged 15-19 reported one or more casual sexual encounters (Mehra, Savithri and Coutinho 2002a).

\section{Lack of contraceptive or condom use}

Lack of contraceptive or condom use characterise the vast majority of sexual encounters among youth. Adolescents worldwide are less likely than adults to use contraception, either in or out of marriage, and this appears to be equally true in India. Discontinuation and failure rates are more pronounced among adolescents than among older couples (Singh 1998). There is evidence from the 1998-99 National Family Health Survey (NFHS-2) for example, that only 8 per cent of married women aged 15-19 were using any method of contraception at the time of the survey in 1998-99, and 5 per cent were using a modern method. Regional variation in contraceptive practice is relatively narrow in these ages — notable are such states as Punjab and West Bengal in which 17 per cent and 33 per cent of currently married adolescents respectively reported current contraceptive practice. As a result, some 15 per cent of births to adolescents aged 15-19 in India were reportedly unplanned (Pachauri and Santhya 2003). Indeed, 27 per cent expressed an unmet need for contraception (IIPS and ORC Macro 2000), a figure considerably higher than what is reported in countries of East and South-East Asia (under 5 per cent). Considerable state-wise variation is observed as a result of differential family size preferences on the one hand and access to contraceptive supplies on the other: unmet need is reported by under 10 per cent of adolescents in Punjab and Haryana and by around one-third or more in such states as Bihar, Jammu and Kashmir, Rajasthan, Maharashtra and even Kerala (see Appendix Table 3).

Few studies have explored contraceptive or condom use by the unmarried, and those that do report exclusively on young males. The available evidence suggests that contraceptive use is infrequent and irregular. In a case study of adolescent males in a slum setting in Lucknow, among the sexually experienced, 32 per cent reported condom use in relations with sex workers and 56 per cent in relations with a friend or relative. Protection against pregnancy appears to motivate most condom use (Awasthi, Nichter and Pande 2000). Similarly, among male college students in Mumbai, fewer than half the sexually active had ever used a condom or any other form of contraception (Abraham and Kumar 1999). These students were more likely to report contraceptive/condom 
use in relations with sex workers than in relations with regular or "casual" partners. Even so, the proportion reporting regular use was small and depended on the perceived riskiness of the partner: while 12-13 per cent reported regular use with steady or "casual" partners, not a single male reported regular condom use with sex workers (see Table 2; Abraham 2003; Abraham and Kumar 1999). Leading reasons for non-use of condoms were the spontaneity of sex, lack of awareness of the condom as a means of protection or how to procure condoms, and the perception that condom use reduces pleasure (Abraham 2003).

\section{Table 2: Frequency of condom use among sexually experienced male students by type of partner, Mumbai: \% distribution}

\begin{tabular}{|l|l|l|c|}
\hline & $\begin{array}{l}\text { Regular } \\
\text { partner } \\
(\mathbf{n = 1 6 5})\end{array}$ & $\begin{array}{l}\text { Casual } \\
\text { partner } \\
(\mathbf{n = 1 6 5})\end{array}$ & $\begin{array}{l}\text { Sex } \\
\text { worker } \\
(\mathbf{n = 2 9})\end{array}$ \\
\hline Never & 52 & 57 & $(0)$ \\
Once & 15 & $(7)$ & $(45)$ \\
Sometimes & 12 & 10 & $(14)$ \\
Always & 12 & 13 & $(0)$ \\
No response & 10 & 13 & $(41)$ \\
\hline
\end{tabular}

Source: Abraham et al. 2003

() indicates $<15$ cases

The NACO National Behavioural Surveillance Survey underscores the lack of consistent condom use in casual relationships among youth at the national level (NACO and UNICEF 2002). Approximately half of young females and males reporting casual sex had used a condom at the last sexual encounter; however, only 25 per cent and 37 per cent of males and 24 per cent and 28 per cent of females aged 15-19 in rural and urban areas, respectively, reported consistent condom use in all casual encounters in the 12 months preceding the survey. State-wise variation is evident but by and large, fewer than half of all those reporting a casual sexual experience report consistent condom use in most states (see Appendix Table 2).

\section{Non-consensual sexual activity among adolescents}

Given the sensitivity of the topic, non-consensual sexual activity is rarely reported or studied and may well be under-reported in available studies. Nevertheless, findings from the few available studies offer considerable insight. For example, evidence suggests that a sizeable number of adolescent girls as well as boys are subjected to forced sexual relations. A study of 16-year-old 
school-going adolescents in Goa found that 7 per cent and 6 per cent of boys and girls reported forced sexual relations and 13 per cent and 18 per cent of boys and girls reported unwanted touch (Patel and Andrew 2001). Findings from a qualitative study of adolescents in a Delhi slum reinforce these findings: for several girls, sexual initiation was accompanied by force and fear, both in and out of marriage (Sodhi and Verma 2003). Likewise, in a study of college students from low-income groups in Mumbai, many girls reported being "touched" by the opposite sex at a young age. Girls also reported humiliation and helplessness, and attributed their reluctance to seek help to the fear of drawing attention to their bodies and even to a sense of self-blame in that they may have somehow provoked the incident (Abraham 2001).

What is evident from the findings of the study in Goa is that while forced sexual intercourse is the tip of the iceberg, significantly larger percentages of young people have experienced unwanted touch of private parts (see Figure 2; Patel and Andrew 2001).

Young married women also experience coercion. For example, in studies in rural Uttar Pradesh and Mumbai, the majority of married women described early sexual encounters with their husbands as coercive (George and Jaswal 1995; Khan et al. 1997). Their findings highlight the vulnerability of newly married — usually adolescent — women, who typically described their first sexual experience as "traumatic," "distasteful," "painful" and "frequently forced". In a more recent study of young married women in Kolkata, though reported by only a few, women narrated instances where the exercise of sexual choice was met with marital conflict and the threat of remarriage:

I decided to stop it [sexual relations] since I used to feel uneasy while having sex with a big abdomen. But my husband used to get angry if I told him that I did not want to have sex. He used to tell me that he would remarry if I refused to have sex with him. I tried to explain to him, but he did not want to listen. He used to get angry if I refused and we had some tiffs on this issue. I had to give in to his demands after a few days and our tiffs were resolved. We continued in this manner till my ninth month. I had feelings of discomfort but I had to accept my husband's wishes. (18-year-old recently delivered mother; Santhya, McGrory and Haberland 2001)

While gender disparities are evident, it is important to recognise that young men and boys also experience non-consensual sex. The Goa study shows, for example, that 7 per cent of boys reported a coercive experience, usually perpetrated by an older male (Patel and Andrew 2001). A study of street boys in Bangalore reports that a large proportion of boys are initiated into coerced sex at an early age, often between 10 and 12 years. According to one of the boys, "older boys come and force 


\section{Figure 2: Percentage of adolescent females and males (16-17 years) in Goa reporting non-consensual sexual experiences}

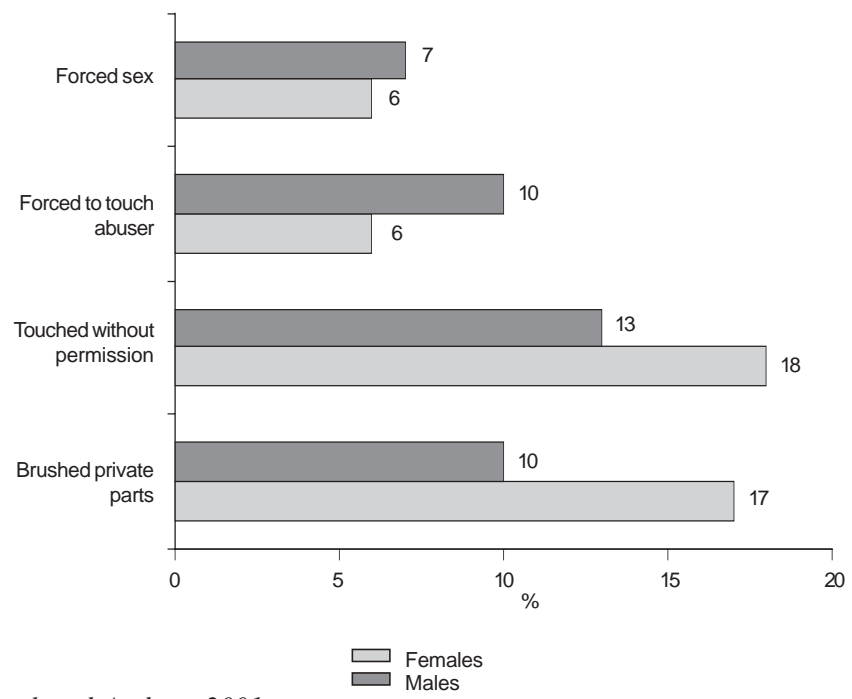

Source: Patel and Andrew 2001

us, when we refuse they beat us. They tell me that they will give money." Sexual coercion is so pervasive on the streets that street boys rated rape and forced sex as among the most pleasurable ways of seeking sexual gratification (Ramakrishna, Karott and Murthy 2003).

\section{Associated risk behaviours}

The dangers that young people face with regard to substance abuse, injuries and violence are increasingly acknowledged. Links are observed, in several developing country settings, between substance abuse and impaired capacity to make decisions on safe sexual behaviour. Studies in India, while relatively sparse, have also recognised these associations. For example, in a study of adolescent boys in urban slums in Lucknow, substance abuse was reported by a substantial minority, and was associated with irregular condom use and sexually transmitted infection (STI) (Awasthi and Pande 1998). Likewise, a study of adolescent truck cleaners reported that of the 210 adolescent boys interviewed, cigarettes were commonly used, and a minority reported extensive use of chewing tobacco, opium and alcohol; links with unprotected sexual relations were also observed (Bansal 1992). Finally, the study of sexual coercion among school-going adolescents in Goa referred to above reports a significant association between substance abuse and sexual coercion (Patel and Andrew 2001). 


\section{Reproductive health outcomes}

\section{Pregnancy and childbearing}

Pregnancy and childbearing characterise the experience of a large proportion of young women in India. Adolescent fertility rates are high: roughly 107 births take place per 1,000 girls aged 15-19, and the fertility of this age group makes up 19 per cent of the nation's total fertility rate (IIPS and ORC Macro 2000). NFHS-2 findings suggest that in many cases pregnancy and childbearing occur even before adolescents are physically fully developed, and may expose young girls to particularly acute health risks during pregnancy and childbirth. Over one in five give birth by age 17 and the median age at first birth is 19 years, suggesting that significant proportions of women undergo pregnancy at ages below which obstetric risks are particularly elevated (IIPS and ORC Macro 2000). Not only does childbearing occur early among married adolescents, but subsequent pregnancies also tend to be more closely spaced than among adults (Santhya and Jejeebhoy 2003). The experience of early and closely spaced childbearing is particularly risky for adolescents because a large proportion are anaemic and may not have reached physical maturity - nearly 15 per cent of ever-married adolescent women were stunted and about one-fifth had moderate to severe anaemia.

The adverse health consequences of early childbearing in these circumstances are well known, including damage to the reproductive tract, maternal mortality, pregnancy complications, perinatal and neonatal mortality and low birth weight (see, for example, Kulkarni 2003). Evidence from community- and facility-based studies reiterate that maternal deaths are considerably higher among adolescents than older women. Estimates derived from a community-based study in rural Andhra Pradesh indicate that in the 1980s the maternal mortality ratio among adolescents was almost twice that of women aged 25-39 (1,484 versus 706-736 respectively; Bhatia 1998). A national study conducted by the Indian Council of Medical Research (ICMR) of 43,550 women in 10 facilities reports that maternal mortality among adolescents was 645 per 100,000 live births compared to 342 per 100,000 among adult women aged 20-34 years (Krishna 1995). Similarly, a study in Mumbai indicates that while the maternal mortality ratio among women aged 20-29 was 138 per 100,000 live births, the ratio among adolescents was considerably higher - 206 per 100,000 live births (Pachauri and Jamshedji 1983). Neonatal mortality, a key outcome of unsafe 
pregnancy conditions, is significantly higher among adolescent mothers than among those aged 20-29: 63.1 and 21.2 per 1,000 live births, respectively (IIPS and ORC Macro 2000).

Appendix Table 4 lists key indicators available at the state level from NFHS-2, namely median age at first birth, extent of anaemia experienced by married adolescents aged 15-19, and neonatal mortality rates among adolescent and women aged 20-29. The familiar disparity between the large northern and eastern states and the rest of India is evident with regard to neonatal mortality: such states as Bihar, Madhya Pradesh, Orissa, Rajasthan and Uttar Pradesh continue to experience exceptionally high rates of neonatal mortality among adolescent (and older) mothers (aged 40-49). State-wise variation is less marked in the case of the remaining indicators, although it is Kerala that reveals the highest median age at first birth and the lowest proportion of anaemic adolescents.

\section{Induced abortion}

As abortion is such a sensitive topic, levels of induced abortion are difficult to measure directly. However, small studies suggest that a substantial proportion of adolescents, both married and unmarried, seek abortion services. It is estimated, for example, that between 1 and 10 per cent of abortion-seekers in India are adolescents (Ganatra 2000), though a few facility-based studies report that the proportion of adolescent abortion-seekers is as high as one in three (Chhabra et al. 1988; Solapurakar and Sangam 1985). An analysis of data from NFHS 1998-99 shows a lifetime induced abortion ratio of 1.1 among married adolescents nationally (Pachauri and Santhya 2002). Among unmarried abortion-seekers, adolescents constitute a disproportionately large percentage. At least one-half of unmarried women seeking abortions at facilities are adolescents, many of whom are below 15 years (Jejeebhoy 2000). A community-based study in rural Maharashtra reports that young women aged 15-24 constituted over half of married abortion-seekers in the area (Ganatra and Hirve 2002). Findings of this study suggest, moreover, that adolescents have considerably less decision-making authority than older abortion-seekers, are more likely to be coerced into an abortion, or conversely, to face opposition from their families, and are more likely to report postabortion morbidity.

\section{Reproductive tract and sexually transmitted infections, including HIV/AIDS}

Few studies have specifically investigated reproductive tract infections (RTIs) and STIs among young people. A community-based study of RTI prevalence among 451 married women aged 16-22 in rural Tamil Nadu underscores the extent to which infections go unnoticed in this outwardly "low-risk" population. Forty-nine per cent of women in the study reported suffering RTI symptoms, 
while clinical and laboratory examination diagnosed 18 per cent with an STI, including chlamydia, trichomoniasis and syphilis. Findings suggest that in many cases husbands may transmit infection to their wives, which is a matter of concern given that many infected women are asymptomatic and are unlikely to seek care even when symptoms appear (Joseph, Prasad and Abraham 2003).

Globally, nearly 45 per cent of all new HIV infections (about 2.4 million per year) occur among 15-24-year-olds, and in several settings, the rate is equal to or more than that estimated among adults. In India, for example, the estimated percentage of young females aged 14-24 living with HIV/AIDS (0.96 and 0.46 per cent in high and low prevalence sites, respectively) exceeds the rate for young men ( 0.46 and 0.20 per cent in high and low prevalence sites, respectively); this compares with a corresponding percentage of 0.80 among adults (UNICEF, UNAIDS and WHO 2002).

According to the NACO National Behavioural Surveillance Survey, some 3 per cent and 5 per cent of young, mostly unmarried males and females, respectively, reported experiencing such symptoms of infection (STIs or RTIs more generally) as discharge, ulcers or sores in the 12 months preceding the survey. These proportions undoubtedly reflect considerable under-reporting (in some states not a single respondent reported symptoms) and hint that awareness of symptoms may be limited among youth (NACO and UNICEF 2002). 


\section{Underlying risk and protective behaviours}

A host of factors inhibit young people from achieving good sexual and reproductive health. Many are structural or cultural, such as poverty and malnutrition, patriarchy, early marriage and limited access to educational and health facilities, which, in turn, influence risk and protective factors at the individual level. Outlined below are a range of risk and protective factors. We discuss the obstacles that have been observed to prevent young people from achieving good health and exercising informed choices, and highlight emerging evidence on actions that protect their sexual and reproductive health and strengthen their ability to make informed choices.

\section{Raising awareness and overcoming misperceptions}

Studies highlight the lack of in-depth awareness of health-promoting actions and risky sexual behaviours among young people. While awareness of contraception and RTIs/STIs and HIV/AIDS may be almost universal at a superficial level, in-depth knowledge of sexual health issues is sketchy. For example, a case study of adolescent girls and boys aged 14-19 residing in slum settings in Allahabad, Uttar Pradesh reports that although a large proportion had heard of STIs (66 per cent and 87 per cent respectively) and contraception (91 per cent and 94 per cent respectively), only 2 per cent could name an STI other than HIV/AIDS, and only 37 per cent of girls, compared to 84 per cent of boys, were aware of the role of condoms in providing protection against infection (Sebastian et al. 2002a).

Similarly, the NACO National Behavioural Surveillance Survey reveals that although 90 per cent and 80 per cent of young males and females aged 15-19 had heard of HIV, state-wise variations are considerable, particularly among females. For example, fewer than 40 per cent of rural women (particularly those aged 15-19) in such states as Bihar, Gujarat, Jharkhand, Madhya Pradesh and Uttar Pradesh were aware of HIV. Evidence from the survey suggests, however, that simple awareness of HIV does not translate into in-depth knowledge of symptoms, modes of transmission or methods of prevention. In general, only 60 and 54 per cent of urban and rural males aged 15-19 and 56 and 45 per cent of females surveyed could accurately identify two methods of prevention, and only 58 per cent of females and males were aware that there is no cure. Awareness of STIs and their links to HIV was even more limited: 28 per cent and 29 per cent of males and females, respectively, had 
heard of STIs, and only 21 per cent and 18 per cent respectively were aware that STI patients have a higher risk of acquiring HIV infection than others. Again, state-wise variations are evident. Of note is the finding (unfortunately not gender disaggregated) that aside from rural-urban and gender disparities in awareness, significant disparities are observed by education and marital status. As expected, better-educated youth are consistently more aware of HIV and protective factors than are others. Also evident is that it is the unmarried who are more likely to be aware of HIV than the married, suggesting that married females may be particularly poorly informed and vulnerable (NACO and UNICEF 2002).

Dangerous misconceptions are, moreover, common. For example, many young people believe that women cannot become pregnant at sexual debut; that symptoms of STIs go away on their own; that one can clearly identify an HIV-infected person by his/her appearance; that pregnancy can occur through physical embrace; or that HIV infection is transmitted through everyday activity or can be prevented by good personal hygiene (Brown et al. 2001). Among young women aged up to 24 years in India, while 37 per cent have heard of AIDS, no more than three in five could identify such risk factors as multiple partner relations ( 57 per cent) or inconsistent condom use (58 per cent). A disturbing finding is that only one-quarter (26 per cent) are aware that a healthy looking person could be HIV-positive (UNICEF, UNAIDS and WHO 2002). Indeed, the NACO National Behavioural Surveillance Survey reports that only 30 and 22 per cent, respectively, of urban and rural males aged 15-19, and 32 and 20 per cent, correspondingly, of young females, harbour no misconceptions about the transmission of HIV (NACO and UNICEF 2002). State-wise variation is substantial. Correct awareness of three leading misconceptions — that mosquito bites and sharing a meal with an infected person do not transmit HIV/AIDS, and that a healthy looking person can transmit HIV/ AIDS - was limited among adolescents in all states, but appears to be particularly limited among those residing in the northern and eastern states. Somewhat surprisingly, while we observe variation by state and rural-urban residence, gender disparities remain narrow in each state (see Appendix Table 5).

Other studies reaffirm these findings. Among adolescents aged 14-19 in Allahabad, for example, 60 per cent of girls and 50 per cent of boys were unaware of the asymptomatic nature of STIs; and 17 per cent of girls and boys reported that if STI symptoms disappear, it means a person is cured of the infection (Sebastian et al. 2002a).

Misperceptions extend to assessments of personal risk made by sexually experienced youth. For example, among sexually active college-going males in Mumbai, fewer than half of those reporting risky behaviours considered themselves at risk of infection, including HIV (Abraham and Kumar 
1999). A study of low-income adolescents in Delhi suggests, similarly, that few sexually active boys showed concern regarding making a partner pregnant (Sodhi and Verma forthcoming).

There is evidence that adolescents are poorly informed even about the physiological changes associated with maturation, including menstruation (Joseph et al. 1997; UNESCO 2000; Vietnam Educational Scientific Institute 1999). Studies in Tamil Nadu and Pondicherry report, for example, that although menarche is associated with considerable ceremonial attention as a rite of passage, few adolescent girls are well informed about the change they are undergoing; rather, what they are well informed about is the kinds of restrictions on movement and behaviour that are expected of a mature girl (Bhattacharyya 1980; 1996; Narayan et al. 2001).

Moreover, adolescents are particularly unlikely to be aware of the services available to them and their right to avail these services. For example, adolescent abortion-seekers in Pune tended to believe that abortion services are not legally available to unmarried women (Ganatra and Hirve 2002).

Gate-keeper attitudes ensure that young people remain poorly informed; gate-keepers typically (mis-)perceive that deliberate withholding or obfuscating of information are protective strategies. Interviews with parents in low-income settings in Delhi reiterate these perceptions:

One does not require much information... in the adolescent age. More information, no doubt, tempts them to do wrong things. (Fathers' group; Mehra, Savithri and Coutinho 2002a)

Why give them so much information at this stage? They will learn when they need to [after marriage]. (Mothers' group; Mehra, Savithri and Coutinho 2002a)

In school settings, population, family life and sex education appears to be only remotely relevant to the concerns of young people, as they focus on biological and scientific information rather than broader issues of sexuality (see, for example, Chakrabarti 2003). A report of an education programme for boys in a Lucknow slum illustrates the range of concerns raised by boys and the extent of disconnect between these concerns and the information provided in typical family life programmes. Of a total of over 150 questions dropped anonymously in a question box, one-third focused on HIV/AIDS, including questions such as: could one get AIDS from kissing, sharing a cigarette, or mosquito bites? Does AIDS always end in death? One-fourth of all questions related to "gupt roga" (STIs). Some wanted to know how one could tell if girls they were about to marry had a condition 
that could give them gupt roga, whether a man could get gupt roga if a woman is menstruating or has discharge, if someone could get STIs from too much sex, what kinds of protective measures could be adopted, and how a condom prevents infection. Many questions concerned masturbation; for instance, whether the body can lose semen without becoming sick or weak, and whether masturbation affects one's virility or ability to impregnate one's wife later in life (Awasthi, Nichter and Pande 2000).

Indeed, studies suggest that leading sources of information on sexual and reproductive matters are those that are not necessarily the most reliable. Television, peers and erotic literature are by far the most commonly cited sources of information although the information they provide is not always accurate. For example, among low-income college boys in Mumbai, erotic materials were the main source of information (Abraham 2001). A study of adolescent girls aged 13-17 in Haryana reports that for almost all, the leading source of information was television (73 per cent) and/or radio (37 per cent) (Singh, Devi and Gupta 1999). The NACO National Behavioural Surveillance Survey suggests that by and large, young people are relatively unexposed to the wide range of media providing messages on HIV/AIDS: while 76 per cent were exposed to such messages on television, far fewer (between one-third and half) were exposed to messages through the radio or newspapers/ magazines, and between 6 per cent and 12 per cent through billboards, pamphlets or films. In contrast, even fewer - about 15 per cent of males and females - were exposed to inter-personal communication on the topic (NACO and UNICEF 2002).

Well-designed interventions have succeeded in raising awareness of risky behaviours and dispelling myths concerning protection among adolescent girls and boys (Awasthi, Nichter and Pande 2000; Sebastian et al. 2002b). Examples include a novel sexuality education and testing programme for adolescents in a Lucknow slum, and a livelihood skills building programme for adolescent girls in the slums of Allahabad, both of which included a strong reproductive health component. In the intervention among adolescent girls, 94 per cent of the matched sample of girls was able to name an STI at midline compared to 67 per cent at baseline. And while 98 per cent knew that pregnancy occurs through sexual contact, only 44 per cent knew this at the baseline. Among adolescent boys in Lucknow, too, knowledge increased dramatically. Before the intervention, between 59 per cent and 66 per cent of boys in both the study and control groups reported knowing that there is more than one type of STI, but few participants were able to describe symptom clusters. In the follow-up survey, knowledge that multiple STIs exist had increased in both groups, but the increase was statistically significant only in the intervention group (from 66 per cent to 83 per cent). At baseline, between 30 per cent and 40 per cent of youth believed that women and men with an STI always show symptoms of their illness; boys in the intervention group scored a statistically significant 
increase in the knowledge that symptoms may not always appear. They also registered significant increases in their knowledge of STI symptoms and in their awareness of how long symptoms of AIDS (and associated diseases) take to become apparent (Awasthi, Nichter and Pande 2000).

However, as evidence from other settings warns, improved awareness is only one of a constellation of necessary actions and by itself is insufficient to change behaviour.

\section{Building self-efficacy, negotiation, life and livelihood skills}

Gender double standards and power imbalances shape young people's lives and often undermine their ability to make informed sexual and reproductive choices. These double standards and imbalances are manifested in different ways among females and males, and among the unmarried and married. For example, the high priority placed on preserving young women's chastity narrows opportunities for girls on many fronts. A number of studies provide evidence of the limited voice that young married and unmarried females exercise in matters relating to their own lives — whether it is continuation of schooling, when and whom to marry, physical mobility, decision making or sexual relations. Young men are affected by a different set of gender-based expectations, including social pressure to have sex at an early age, and a sense of entitlement to sex in and outside of marriage, often under risky conditions.

\section{Among the unmarried}

Adolescent girls are acutely aware of the restrictions that are imposed on them, whether on dress, speech or free movement. In the course of focus group discussions with girls aged 17-19, a study in Delhi reported, for example:

One of the main ways in which we face restrictions on mobility is when we are asked to discontinue school soon after we attain puberty. ...

They [parents] ask us not to go out alone [because] the boys in the locality tease girls a lot and also because the family name will fall into disrepute. (Mehra, Savithri and Coutinho 2002a)

Young people themselves often accept — and even justify — double standards that condone and even encourage premarital relations for males but not for females. Gender disparities are evident: sexual relations and even social interaction between girls and boys are perceived far more negatively 
for girls than for boys. For example, young girls in low-income settings in Delhi reported disapproval of premarital sex (particularly by girls), and often for that matter, even social interaction between unrelated women and men. As many as 80 per cent perceived that friendships between girls and boys were unacceptable, over 80 per cent reported that girls who engage in premarital sex always regret it and about two-thirds reported that boys do not respect girls who have engaged in premarital sex. Many young girls in this study reported that even the hint of a friendship with a boy could ruin a girl's reputation, her marriage prospects and the social status of her entire family (Mehra, Savithri and Coutinho 2002a; 2002b).

Boys report similar perceptions for girls but are far more likely to condone sexual relations for themselves. For example, in the Delhi study cited above, only 25 per cent of young males reported that friendship with girls was unacceptable (Mehra, Savithri and Coutinho 2002a). In a study of low-income college students in Mumbai, boys argued that it was permissible for them to have premarital sex but not for their future wives: "If she isn't like this [virgin] then I won't marry her" (male, Class 11; Abraham 2001).

While few studies have considered social constraints on adolescent boys, their behaviour is clearly less closely supervised than that of girls' and there is far less concern for their reputation than that of girls (Mehra, Savithri and Coutinho 2002b; Sodhi and Verma 2003). For example:

.... if the girl says no, then boys defame her in her gali [lane] and colony...there is no effect on the boy's character. (19-year-old male student; Sodhi and Verma 2003)

Relatively few girls report a sexual relationship, and those who do clearly report unequal power relations with their partner. Young women are more likely than men to report love and commitment as leading reasons for engaging in sexual relations. Case studies suggest that fear of losing a partner, incurring his anger or jeopardising the relationship are important factors inhibiting young women from exercising choice over whether and when to have sex, and whether to use condoms. The following statement by a respondent in a slum setting in Delhi is indicative:

[Boyfriend] kissed me forcefully...he gets angry if I talk to anyone in the lane. One day he saw me talking to my brother...he... beat me up. He said the boy was my boyfriend... he beat me so much even then I did not say anything to him because I love him so much. (In-depth interview, 15-year-old girl; Sodhi and Verma 2003) 


\section{Marriage-related decision-making}

Arranged marriages and large dowries continue to characterise marriage in most parts of India, in both the north and south. A recent case study exploring marriage patterns among successive cohorts of women in rural Uttar Pradesh and Tamil Nadu concludes that for the overwhelming majority in both settings, irrespective of age, region or religion, marriages are arranged either by the parents alone or with the help of relatives and matchmakers. Yet subtle differences emerged, and substantial minorities of women reported having a say or being consulted in these decisions. While the familiar north-south disparities are observed, age-specific differences are also evident within each setting. For example, among south Indian Hindus, the proportion reporting a say in marriage decisions increased from 33 per cent in the oldest cohort (aged 32-39) to over half (53 per cent) in the youngest; Muslims report somewhat less spectacular increases correspondingly, from 25 per cent to 37 per cent. In contrast, cohort-specific changes among women from Uttar Pradesh, irrespective of religion, are modest. Even among young women in Uttar Pradesh, no more than a handful — one in 10 Hindus and one in eight Muslims — have a say or veto powers in this decision (Jejeebhoy and Halli 2002).

Among low-income college girls in Mumbai, an arranged marriage is an unquestioned norm (Abraham 2001). Girls reported that they were likely to have an arranged marriage; indeed many preferred an arranged marriage as it was perceived to provide stability and security, and as being the responsibility of the natal family:

When people at home have arranged the marriage, then even if the in-laws ill-treat [the wife], then the family can be blamed for arranging it. When parents arrange the marriage, then much of the responsibility is on them. (Girl studying in 3rd year college; Abraham 2001)

However, it is clear that girls would like to have more of a say in marriage decisions than they currently have. In-depth interviews with first-time pregnant women and first-time recently delivered mothers in Vadodara and Kolkata reiterate this finding (Haberland, McGrory and Santhya 2001; Santhya, McGrory and Haberland 2001). Young women reported that they rarely had a say in marriage decisions; the typical response was:

Did I get the chance to say anything? Could I say anything after my parents took the decision? What could I have done? (18-year-old recently delivered mother in Kolkata; Santhya, McGrory and Haberland 2001) 
Some young women implied moreover that they were married early against their will at the behest of their parents:

... at that time I did not want to marry as it was too soon. So I told my mother about it but she did not agree and said that I will have to get married early. So then, as I liked him, I said yes. (17-year-old girl in Vadodara; Santhya, McGrory and Haberland 2001)

There is some evidence, however, that practices may be changing. In Kolkata, for example, eight out of 30 couples reported that they had made an independent decision on when and whom to marry (Santhya, McGrory and Haberland 2001).

\section{Among the married}

Within the age and gender-stratified family structure that is characteristic of most of India, young, newly married women face huge constraints on their autonomy in the marital home. The average adolescent bride is unlikely to have a say in whether or not to have sexual relations, and when to bear children. On the contrary, society often places pressure on them to prove their fertility, and in many settings bearing sons is the only means by which young women can establish social acceptance and economic security in their marital homes. Married girls often have limited access to health care and decision-making authority (Barua and Kurz 2001; Kulkarni 2003; Santhya and Jejeebhoy 2003). An analysis of NFHS data shows, for example, that although decision-making authority is limited among women in general, married adolescents are particularly unlikely to participate in household decisions, whether those relating to major purchases or to their own health care. What is noteworthy is that age plays a more powerful role in enhancing participation in decision-making than other socio-demographic factors, including education. For example, an uneducated older woman is significantly more likely to have decision-making authority than either an uneducated married woman aged 15-19 or an adolescent who has passed secondary school (Santhya and Jejeebhoy 2003).

\section{Promising approaches}

While limited, however, there is evidence of young girls making decisions on whether or not to engage in a partnership, when and whom to marry and on matters affecting their own lives more generally. Although sparse, findings from in-depth interviews suggest that even in highly constrained 
settings, some adolescent girls do indeed negotiate wanted outcomes, as suggested in the following accounts of low-income adolescents in two studies in Delhi:

He said that he loved me, but I didn't love him.... Then I asked about him from some of his friends, about his behaviour and habits. His friends told me that he is a very nice boy... I thought about it for several days and decided that I should have a friendship [dosti] with him. (17-year-old girl; Sodhi and Verma forthcoming)

I prefer to call the boys "bhai" [brother], that is the only way to make sure that they will not make any sexual advances towards you. (17-year-old girl; Mehra, Savithri and Coutinho 2002a)

Over the last decade, an increasing number of programmes intended to enhance negotiation, life and livelihood skills among young females have been implemented both in the government and non-governmental sectors. For the most part, these programmes are poorly evaluated and their feasibility, effectiveness and acceptability poorly understood. There are however some exceptions. At least two studies have documented increases in self-efficacy and autonomy among adolescent girls who participated in, respectively, a comprehensive education and service intervention and a livelihoods and vocational training programme. One study followed a cohort of out-of-school adolescent girls two to five years after they were exposed to a comprehensive education and service intervention. The study found that self-efficacy was significantly enhanced among programme participants compared to a corresponding set of unexposed girls. The intervention provided non-formal, family life and vocational education as well as service provision, opportunities to learn how to use banks and public transport, to participate in recreational activities and to receive leadership training. Those who participated in the programme were, for example, more likely to display autonomy and self-confidence, and more likely to make independent decisions. They were also more likely to be engaged in economic activity ( 35 per cent vs. 8 per cent), and more likely to participate in decisions on marriage ( 25 per cent vs. 7 per cent), going to the market ( 52 per cent vs. 27 per cent) and how to spend money earned ( 42 per cent vs. 12 per cent of working girls). They were more likely to have travelled alone outside their village (68 per cent vs. 21 per cent) and to have gone to a health centre alone ( 25 per cent vs. 6 per cent) in the last six months. These differences in autonomy were significant even after controlling for education of girls and their parents. In terms of reproductive health-seeking behaviour, as Figure 3 suggests, those who had married in the interval $(\mathrm{n}=292)$ reported significantly more positive behaviours compared to married controls $(n=269)$ for a host of indicators related to reproductive health and child survival: they were more likely to have married at age 18 or above, to use contraception and to have sought pregnancy-related care if they became pregnant (Levitt-Dayal et al. 2003). 
The second is an ongoing demonstration project focusing on building skills among adolescent girls and specifically to expand a pre-existing reproductive health programme for girls aged 14-19 to include counselling on savings formation and livelihoods, training in vocational skills, assistance in opening savings accounts and follow-up support. A comparison of data collected at baseline and data collected a year later at midline suggests changes in participants' mobility, gender role attitudes, decision-making and self-confidence. The objective of the study is to explore the extent to which such programmes succeed in building self-efficacy among adolescent girls, developing work and savings orientation, increasing knowledge of sexual and reproductive health issues and empowering them to exercise and negotiate informed choices. Preliminary findings are encouraging. For example, among the matched sample, over 75 per cent reported that they could go alone to visit a friend, compared to fewer than 33 per cent at baseline; 58 per cent reported that they could go to nearby health facilities alone compared to 18 per cent at baseline. Similarly, almost half the matched sample of girls felt that they could convince other people of something they believe in at the time of the midline survey, a substantial increase from 18 per cent during the baseline survey. Seventytwo per cent are now confident talking in front of a group, whereas only 36 per cent reported such confidence at the baseline. When asked at the midline whether "boys make better leaders than girls," 23 per cent said "yes," a decrease from 68 per cent at the baseline (Sebastian et al. 2002b).

\section{Figure 3: Intervention participants and non-participants reporting selected reproductive health behaviours (\%)}

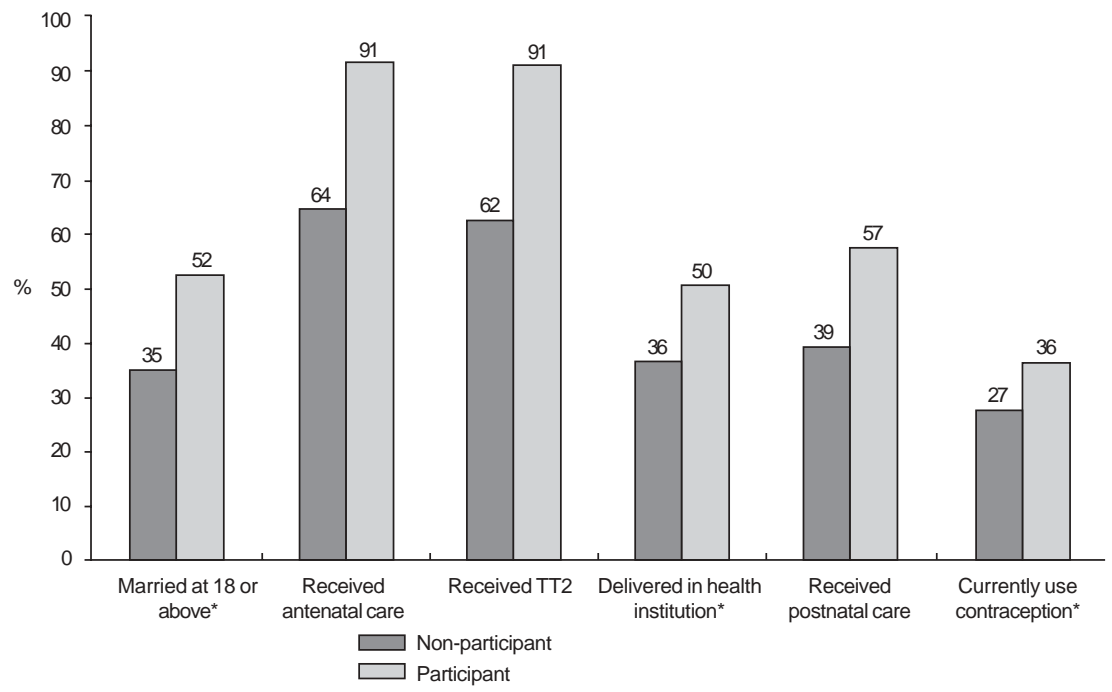

Source: Levitt-Dayal et al. 2003.

* Becomes non-significant when controlling for girls' education. 
In short, programmes have increasingly recognised that the exercise of reproductive choices is significantly strengthened through the development of life and livelihood skills.

\section{Strengthening linkages with parents: Communication, interaction and support on sexual and reproductive health matters}

Neither communication, interaction nor support characterise the relationship between adults and their adolescent children with regard to matters relating to sex and reproduction as these issues remain taboo within families (Abraham 2001; Masilamani 2003; Mehra, Savithri and Coutinho 2002a). Indeed, parental counselling is often so limited that many adolescent girls report that parents did not discuss menstruation with them until it occurred (Abraham 2001; Jejeebhoy 2000). In many cases, parents believe that talking to adolescents about these issues would imply approval of sexual activity (Masilamani 2003).

Few studies have explored the ways in which the nature of parent-child relationships is related to risky sexual and reproductive outcomes among adolescents (see, for example, Abraham 2001; Mehra, Savithri and Coutinho 2002a; 2002b). Findings suggest that concern for the sexual security and chastity of daughters dominates parental relationships with adolescent girls. Interaction with daughters focuses largely on "dos and don'ts" of acceptable behaviour, and on supervision or policing of their activities and behaviours. In contrast, interaction with sons is far more permissive. As described earlier, studies in a low-income setting in Delhi describe the extent to which communication with daughters was dominated by monitoring of the clothes they wore, their physical appearance, their movements (to the point of withdrawing them from school or watching them walk to the common toilets), and their social interaction with peers, even other girls (Mehra, Savithri and Coutinho 2002a; 2002b). College students in Mumbai reported similar concerns among parents (Abraham 2001). For example:

At home they used to tell that stay away from boys, don't go much close to them. Then playing with boys got stopped. Then they used to tell that don't talk much with boys. Then talking also became less. (Female, Class 11, Mumbai; Abraham 2001)

Sons, in contrast, are encouraged to attend school, seek employment and socialise with peers outside the home (Abraham 2001; Mehra, Savithri and Coutinho 2002a). Indeed, Abraham (2001) notes that barring a few exceptions, young boys were never told to keep away from girls. 
Findings from focus group discussions and key informant interviews in the Delhi study warn that relationships in which parents take on a policing role may not always safeguard against risky sexual behaviour. Intimate non-sexual and even sexual relations do indeed occur, and unwanted pregnancy and resort to abortion are not unknown, notwithstanding parental perceptions (Mehra, Savithri and Coutinho 2002b). For example:

There are a lot of constraints on girls' movements. But they continue to meet their male friends secretly. When parents learn of these cases they generally forcibly get them married off elsewhere after an abortion or agree to get them married to the same boy. (17-19-year-old girls in an urban slum; Mehra, Savithri and Coutinho 2002b)

One girl came asking for advice as her boyfriend was wanting to have sex with her. We discouraged her saying that he may not marry her later. She should be sure if she still wanted to do so. (NGO worker in an urban slum; Mehra, Savithri and Coutinho 2002b)

There are some cases of pregnancies among unmarried girls...we do have girls of this kind in our area. We do not know them well and do not interact with them. (15-17-year-old girls in a resettlement colony; Mehra, Savithri and Coutinho 2002b)

There are cases of unmarried girls coming for abortions in the area. Two such girls have come to our clinic. They may seek initial advice and if they feel the word will spread, would not return to us. (NGO worker in a resettlement colony; Mehra, Savithri and Coutinho 2002b)

There is evidence however that parents increasingly recognise the importance of raising awareness among their adolescent children, but are inhibited by their own inadequate knowledge of the subject on the one hand, and their own embarrassment about raising these issues with their children on the other (Damayanthi 2003; Sebastian et al. 2003; Subba Rao 2003). In a study of adolescents aged 14-19 in slum settings in Allahabad for example, only 25 per cent of mothers and 30 per cent of fathers reported that they were confident about their own awareness of reproductive health matters, and almost all - 89 per cent of mothers and 95 per cent of fathers — preferred that reproductive health matters be imparted to their daughters by NGOs or in a school setting (Sebastian et al. 2003). 
Few studies have explored the links between parental support and protection from risk. Those that do hint that family support may be key in influencing safe sex behaviours. For example, a study of low-income college students in Mumbai reveals a positive relationship between perceived authoritarian family relationships and early sexual debut among young males (Abraham and Kumar 1999). Another study of 16-year-old students in Goa suggests however that adolescents - especially girls - who experience unwanted sexual relations are more likely than others to report lack of communication and support in relationships with their parents (Patel and Andrew 2001). And a recent study of adolescent abortion-seekers suggests that fear of parents, fear of disclosure of pregnancy status and lack of perceived parental support may have led many pregnant adolescents to delay an abortion or to seek an abortion from unqualified providers (Ganatra and Hirve 2002).

The importance of communication and support in parental relationships was strongly stated, similarly, by young people who attended a South Asia Conference on Adolescents in New Delhi in 1998:

Our perspective is that we feel neglected, and so we need more attention, care and support from all. We feel we do not have the right to make our own choices, even after learning about all the alternatives and choices related to our careers, friends, movements and life partners. We greatly lack proper and correct information and guidance, especially related to our bodies' physiological and psychological changes. We are not allowed to express our emotions and our thoughts. To our parents, we say that we need you to listen to us, to our dreams, our experiences, our explanations. Give us your time - you gave us life, now we want your time. Don't hide things from us, especially when they are related to us. Give us the privacy and the space to grow. Guide us; don't drive us. (UNFPA 1998; quoted in Singh 2003)

Speculating from this admittedly slim body of evidence, it appears that the strict parental supervision and control that characterise the lives of adolescents, especially girls, do not necessarily protect adolescents from risky sexual and reproductive outcomes. Rather, it is the extent to which parental relationships are characterised by communication and support that may be key, and strategies are needed to build this relationship.

\section{Making programmes youth-centred and youth-led}

Although there are a host of laws and programmes intended to protect aspects of young people's sexual and reproductive health and the ability to exercise their rights, they have rarely been 
implemented in ways that address the needs of adolescents, whether married or unmarried. As a consequence, appropriate health seeking for sexual and reproductive matters remains compromised among young people, particularly young females.

Take the issue of adolescent marriage, for example. It is well known that the law stipulating the minimum age at marriage remains unenforced, that a large proportion of young women marry and bear children in adolescence, and that few married young women have autonomy over their sexual and reproductive lives. Nevertheless, few programmes exist that address married adolescents as a distinct group, make a concerted effort to delay early marriage, postpone early childbearing or recognise the significant barriers imposed on their mobility or health-seeking decision-making. Hence, their needs remain under-served. For example, despite knowledge of the limited autonomy of married young women and the adverse consequences of pregnancy in adolescence, contraception is rarely offered to the newly married, on the assumption that delaying the first birth is culturally unacceptable.

At the same time, few programmes explicitly ensure that adolescents receive antenatal or intra-partum care. The result is that they are no more likely to receive pregnancy-related services than adult women are - and in some states less likely to (IIPS and ORC Macro 2000; Santhya and Jejeebhoy 2003). Almost one-third of adolescents who gave birth in the three years preceding the NFHS-2 received no antenatal care, 32 per cent delivered in an institution and 42 per cent were delivered by a trained attendant. Of those delivering at home, only 18 per cent were followed up in the postpartum period. As Appendix Table 6 suggests, there is considerable state-wise variation in pregnancy-related care of adolescents. By and large it is the northern states in which pregnancyrelated care of adolescents is particularly limited — in such states as Haryana, Rajasthan, Madhya Pradesh, Uttar Pradesh and Bihar for example, 40 per cent or more recently delivered adolescents had received no antenatal care, fewer than one-quarter had delivered in an institution, and fewer than one-third were delivered by a trained attendant. In contrast, in Punjab, and the western and southern states, considerably larger proportions had received pregnancy-related care. Even so, care is by no means universal.

Nor do programmes attend to young married women's needs for care of gynaecological disorders. For example, in a study of married young women in rural Maharashtra, only 49 per cent of those who experienced a gynaecological problem sought care (Barua and Kurz 2001). In another study in rural Tamil Nadu, only 9 per cent of those aged up to 22 years who experienced RTI/STI symptoms sought treatment (Joseph, Prasad and Abraham 2003). 
Unmarried young people do not fare any better. Numerous studies suggest, for example, that adolescents would like to know more about their bodies, relationships, sex and reproduction; yet neither counselling nor sexuality education reaches them. Findings reported earlier of irregular contraceptive use in premarital sexual partnerships suggest that access to condoms and contraception is also limited. It is a matter of concern that sexually active young people are ineligible for the contraceptive services offered by the Family Welfare Programme; the focus on delivery of contraceptive supplies to "eligible couples" makes unmarried young people ineligible to avail such methods from health workers. The only contraceptive outlets available to them outside the private sector, therefore, are social marketing outlets.

Access to abortion services is considerably more limited among unmarried young females compared to adult women, and even married young women. Evidence suggests that adolescents - particularly unmarried adolescents - are more likely than older women to seek abortions from unqualified or untrained providers, to have delayed abortion and undergo second trimester abortions, and to suffer complications (Jejeebhoy 2000; Solapurakar and Sangam 1985). Lack of access to services and other resources are factors contributing to adolescents' reluctance to seek safe and early abortions on the one hand, and to seek care in case of complications on the other. Unqualified or traditional providers are frequently preferred because they are perceived as providing prompt and anonymous care. There is evidence that, in some cases, providers charged unmarried women more for their services (Ganatra and Hirve 2003).

Care seeking for symptoms of infection is limited. The NACO National Behavioural Surveillance Survey reports that fewer than half of all symptomatic young men and about one-third of all young women, mostly unmarried, sought medical care for their symptoms (NACO and UNICEF 2002).

Factors impeding the use of services by unmarried youth have not been adequately studied in India. We know, as mentioned earlier, that the Family Welfare Programme effectively denies unmarried young people access to contraceptive information and supplies, focusing the activities of its peripheral health workers on the married. Other obstacles commonly cited by unmarried youth in other settings include a range of provider-related and facility-based obstacles - limited accessibility, high cost, lack of privacy and confidentiality, poor counselling skills, threatening provider attitudes and indifferent quality of care (Senderowitz 1999). Indeed, findings from a study in neighbouring Bangladesh reinforce this: most unmarried adolescents perceive that they would not be treated respectfully if they visited clinics or pharmacies for family planning or STI services. Providers are perceived as judgmental and unfriendly, and many providers themselves express negative attitudes, disapproval of premarital sex particularly for girls, and uneasy interactions with young unmarried clients (Bhuiya et al. 2003). 
While the need to provide accessible and friendly services to youth is acknowledged, there is less clarity about what is meant by "youth-friendly". It is evident that young people want to access confidential services without fear of discovery by family or community members; that services are available at convenient locations and times, with minimum waiting time, are affordable, and most important, provided by staff who are unthreatening, non-judgmental and willing to respect confidentiality. There is a suggestion that in India where anonymity is assured (e.g. telephone hotlines or the letter-box approach to communication and counselling), adolescents do indeed take steps to obtain information. "Youth-friendly" services have been established in several locations and are intended to enable access to an array of non-judgemental and confidential services. One such facility has recently been established in a dedicated space in a government hospital in New Delhi and its effectiveness in serving young clients is yet to be empirically established (Mehta 2003). Lessons learned from a similar experience in Thailand suggest that hospital settings may not attract young people however friendly the services; rather, there is a need to house services at more acceptable locations such as department stores, youth centres, colleges and universities (Poonkhum 2003). Indeed, a study in rural South India that sought the perceptions of adolescent girls on acceptable health services reports that girls expressed the need for a separate clinic for young people served by female providers (Joseph et al. 1997).

An example in India where services are provided to adolescents in a safe and private setting is Sangath's adolescent and family programme in Goa. Sangath's approach encompasses two major principles. First, services are based on the recognition that fulfilling educational needs, access to appropriate services and parental communication are key to healthy adolescence. Second, services are delivered in ways that accommodate young people's stated priorities: "a welcoming facility, where I can drop in and be attended to quickly," "where there is privacy and confidentiality," "where staff treat us with respect and do not judge us," and "where we can get a range of services so that we do not have to be referred to different places for treatment" (Godinho et al. 2002).

In short, actions intended to enhance reproductive health and the exercise of informed choice need to recognise that young people are a heterogeneous group whose situation, vulnerabilities, strengths and needs vary greatly by sex, age and marital status, as well as by schooling and work status, family and economic conditions. At the same time, actions must encompass young people's needs and priorities such as, for example, for education, counselling and building links to services, even those that go beyond the health sector, notably life and livelihood skills building. Finally, programmes need to involve a wide constituency, including parents, teachers, and religious and community leaders (Bott et al. 2003). 


\section{Changing policy and programme environment}

Over the course of the 1990s, the policy environment has begun to shed its ambivalence on the need to address the sexual and reproductive health needs of young people. Several landmark events - notably the International Conference on Population and Development (ICPD) Programme of Action at the international level and the shift away from targets towards a client-centred approach at the national level, have had considerable direct and indirect consequences for programmes for youth. At the international level, the ICPD and ICPD+5 have reiterated the importance of providing information, counselling and services for youth, achieving universal access to primary education, closing the gender gap in primary and secondary school education, and, more generally, respecting the reproductive rights of adolescents and youth. Indeed, by 1999, the recommendations of ICPD+5 included the recognition of young people's vulnerability to HIV and suggested attention to reducing prevalence in this age group. Other notable conventions ratified by India that have implications for addressing the reproductive and sexual rights of young people include, most notably, the Convention on the Rights of the Child (CRC) and the Convention on the Elimination of All Forms of Discrimination Against Women (CEDAW).

At the national level, these commitments to meeting young people's sexual and reproductive health needs and rights have been recognised. While the overarching goals of the National Population Policy 2000 are to address unmet needs for contraception, provide integrated service delivery for basic reproductive and child health care, and achieve a stable population by 2045 , it recognises, for the first time, that adolescents constitute an under-served group with special sexual and reproductive health needs that have remained unmet. The Policy advocates special programmatic attention to delay marital age, provide free and compulsory education up to the age of 14 and provide nutritional services. It specifically recommends the need to "ensure for adolescents access to information, counselling and services, including reproductive health services, that are affordable and accessible," and to "strengthen primary health centres and sub-centres to provide counselling, both to adolescents and also to newly weds" (MOHFW 2000).

Moreover, the changing contours of the HIV/AIDS epidemic in India and recognition of its spread among young people has resulted in a greater openness in addressing issues relating to sex among young people. The National AIDS Policy 2000, for example, focuses on the population between 
18-40 years, and discusses more directly, measures to address risky sexual behaviour, but does not identify adolescents and youth as a special group.

The draft National Youth Policy 2000, addressing the needs of those aged 13-35, stresses the need for a multi-sectoral approach to youth, with a focus on "youth empowerment," notably education, skills building and leadership as well as nutrition and equal opportunity. While it discusses the need for access to health services among young people, particularly women, and cites the need for reproductive health "guidance," population and family life education, its primary focus is nutrition and education rather than sexual and reproductive health.

In connection with the preparation of the Tenth Five-year Plan (2002-07), a Working Group for the Welfare and Development of Adolescents was established to provide input into the Plan. Its report makes recommendations pertaining to all aspects of adolescent life. It notes the need for more meaningful education (formal and non-formal, life skills and livelihood training); advocates changes in the conditions of working adolescents and attention to the kinds of work that adolescents "can and cannot" do; stresses gender issues and the different needs of boys and girls; and highlights the health and nutrition needs of adolescents and the need for counselling, a supportive environment and youth participation in development planning. It also focuses on issues of national integration and sports and adventure, and notes the needs of adolescents in difficult circumstances. The Working Group advocated that the most appropriate location for issues of adolescence is the Ministry of Youth Affairs and Sports, but recognised the need to substantially strengthen this Ministry and expand its mandate to address adolescents in a meaningful way. It recommended moreover a decentralised approach focused on municipal, taluka and panchayat levels (Planning Commission 2001).

Several programmes have been undertaken at the national level that translate the recommendations of these policies into action. The Reproductive and Child Health Programme ( $\mathrm{RCH}-\mathrm{I})$, whose second phase is soon to be launched, made a paradigm shift in the mid-1990s, away from contraceptive targets to a client-centred focus on health needs, better quality gender-sensitive information and services, and ensuring access. While the programme recognised that youth are a special population with special needs, specific measures to ensure their sexual and reproductive health and rights have not been implemented under this programme. For example, while married adolescents are especially vulnerable, the programme has made no special attempts to ensure delayed or safe pregnancy among them; and despite increasing evidence of unsafe sexual activity among the unmarried, the programme has effectively denied the unmarried access to contraceptive services. 
The second phase of the Reproductive and Child Health Programme (RCH-II) is currently (late 2003) in design phase. A draft Programme Implementation Plan however suggests that the programme will pay considerable attention to adolescent health. It proposes, in a phased manner, an adolescent health initiative comprising two significant components: adolescentfriendly health services and adolescent health counselling services. Only 75 (or 12 per cent) of the country's districts will be covered in the first phase. Despite the government's commitment to addressing the sexual and reproductive health needs of youth however, the components ennvisaged fall disappointingly short of addressing needs in two major ways. There is no recognition, for example, that adolescents are not a homogeneous group indeed, aside from distinguishing between the counselling needs of younger and older adolescents, the draft plan appears to overlook the heterogeneous needs of male and female adolescents, and the married and unmarried. Indeed, no mention is made of services to the unmarried. Moreover, among the array of adolescent-friendly health services listed - nutrition advice and detection of and treatment for anaemia, antenatal care and advice regarding childbirth, and even easy and confidential access to abortion and services for RTI/STI/HIV detection and counselling and treatment of RTIs and STIs - the contraceptive service needs of youth are conspicuously absent and it is unclear how the programme proposes to serve the contraceptive needs of young people (MOHFW 2003).

The Ministry of Youth Affairs and Sports undertakes programmes, under the broad umbrella of the Nehru Yuvak Kendras, to raise health awareness and adopt health-promoting practices, particularly with regard to issues relating to sexual and reproductive health. Activities also include livelihood skills development and training in self-employment. Programmes are being implemented unevenly across states (see for example the assessment of the Working Group for the Welfare and Development of Adolescents, Planning Commission 2001).

At the state level, various innovations have been initiated. Several states have introduced specific programmes for youth, including in school and community settings. For example, in Andhra Pradesh, the Education Department launched a four-day AIDS education programme, including a life skills focus, in school settings. The programme experience concluded that adult gatekeepers - parents and teachers in particular — may pose a significant challenge in promoting school-based awareness. There was considerable demand for the programme among young people, and was perceived by them to be an appropriate mechanism through which sexual and reproductive health awareness can be imparted. Considerable demand for an extension of such programmes has also been generated both among students and out-ofschool youth (Damayanthi 2003). 
There are, moreover, a number of programmes in different parts of the country that do not focus directly on the sexual and reproductive health of young people, notably girls, but attempt to build skills and livelihoods, provide training and education, or more generally, empower girls in ways that may have a bearing on their sexual and reproductive health awareness and exercise of rerpoductive choices. For example, the Indira Soochana Shakti Yojana, the Balika Samriddhi Yojana, the Kishori Shakti Yojana, the Shagun Scheme (Punjab), and schemes operating under the Integrated Child Development Services (ICDS) programme offer girls training in thrift, credit services, health, hygiene and so on. Other schemes - notably the Apni Beti, Apna Dhan scheme and the Rajalakshmi scheme of Unit Trust of India - offer families monetary incentives for delaying the marriage age of their daughters beyond 18; under these schemes, insurance policies are drawn up in the girl's name and mature in her name if she has not married by age 18. While an array of schemes exist, they have limited reach and have rarely been evaluated. 


\section{Conclusions and recommendations}

The picture that emerges suggests that substantial proportions of young people experience risky or unwanted sexual activity, do not receive prompt or appropriate care, and experience adverse reproductive health outcomes. Contextual factors such as poverty, gender imbalances and lack of education or livelihood opportunities clearly increase the vulnerability of youth. Other factors at the family, community and facility level may also exacerbate risk. While young people's knowledge and awareness of sexual and reproductive health is increasing, much of this knowledge remains superficial and ridden with myths, misperceptions and a sense of invulnerability. Gender power imbalances make risky behaviours acceptable, encourage secrecy and fear of disclosure, and inhibit negotiation among partners. Lack of communication with parents and other trusted adults, similarly, keeps young people ill informed and unlikely to receive parental support or counsel in relation to sexual matters. Sexuality education remains inadequate and irrelevant to young people's needs, and services remain inaccessible, unacceptable, unaffordable and of indifferent quality.

Several encouraging signs are, however, evident. The sexual and reproductive health needs of adolescents and young people are on the national agenda. There is growing recognition that young people themselves must be given a role in articulating, designing, implementing and evaluating such programmes. Finally, experiences of a few programmes already exist that appear to successfully respond to young people's sexual and reproductive health needs in innovative and acceptable ways. Building on the evidence from promising interventions and from reports of obstacles, a core set of actions that protect have been highlighted.

\section{- Place sexual and reproductive health within the context of young people's concerns}

Young people are confronted with a rapidly changing world in which social norms are being questioned and new opportunities are becoming available. In this context young people's needs go well beyond the sexual and reproductive health domain. Concerns about schooling, career, financial security and marriage, for example, play an equally and sometimes more important role in young people's lives. Yet programmes remain top-down and do not allow for this multiplicity of concerns 
to be addressed. Programmes need to be designed to cater to the concerns of youth in more holistic and acceptable ways.

An issue that must be addressed is the persistence of early marriage and the special needs of married adolescent girls. There is a need to raise awareness among girls, parents, teachers and community leaders about the negative impact of early marriage and pregnancy on women's and children's health, and to hold the government accountable for enforcing the legal minimum age at marriage for girls. Simultaneously, programmes need to find ways to enhance married girls' autonomy within their marital homes, encourage education, enhance life skills and generate livelihood opportunities. Given the low status of married adolescent girls in many communities, programmes must target not only young married women but also family decision-makers - husbands and mothers-in-law. Health providers need to be trained to recognise married adolescent girls as a "high-risk" group, and offer them information, counselling and services taking into consideration girls' lack of mobility and power within their marital homes.

\section{- Equip young people with knowledge and information on diverse, inter-related issues}

Young people need information ranging from risk and protective sexual behaviours (including the role of condoms) to physical maturation, formation of partnerships, sources of information, counselling and services, their rights in accessing services and exercising choices. Sex and family life education must be imparted in ways that meet the needs of those in school and out-of-school, responding to, rather than obfuscating, their questions on sexual health.

\section{- Build self-efficacy, life, communication and negotiation skills among young people}

Equally important is the acquisition of life skills that enable youth to put information into practice, encourage young people to break down gender stereotypes and relate to each other as equals, develop self-esteem, as well as strengthen abilities in problem-solving, decision-making, communication and inter-personal relations, and negotiation. Programmes that develop positive norms that learn from the experience of "positive deviants" need to be promoted. In this connection, programmes that have successfully built life skills, addressed male involvement in sexual health, and explored livelihood skills building among adolescent girls need to be rigorously documented, evaluated and upscaled. 
- Sensitise parents and other trusted adults to provide more supportive environments for youth

What is needed therefore are actions that sensitise parents and other trusted adults to provide more supportive environments for youth. Parents, teachers and the adult community more generally must facilitate informed decision-making, whether through free and open communication, or by creating environments that protect adolescents from abuse, and enable them to access information and the full range of services. Programmes are needed at the family and community levels that enable parents and other community members to overcome their discomfort, enhance their knowledge of adolescent health and development, and improve their communication skills. Messages about the legal age at marriage, the adverse consequences of early marriage, and the importance of removing gender double standards and imbalances that may adversely affect the lives of both their sons and daughters must be reinforced. Programmes are also needed that highlight the fact that close supervision may not be sufficient to prevent premarital partnerships, and convince parents of the need to focus on enhancing informed choice among adolescents rather than imposing strict supervision and controls as a more effective strategy to ensure sexual and reproductive well-being. Such interventions need to be rigorously evaluated, and those strategies that prove effective more widely applied.

\section{- Adapt programme content and service delivery strategies to be sensitive, attractive and acceptable to youth}

Girls and boys, married and unmarried, have different priorities and needs, and must overcome a different set of obstacles in accessing sexual and reproductive health information and services. In order to be "youth-friendly," programmes and services must recognise young people's special needs, and respect these needs in a supportive and non-threatening manner. The current thrust of the programme may be perceived as inaccessible to young people - for example, effectively denying contraceptive supplies to unmarried youth, neglecting the issue of delaying childbearing among the married, and inattentiveness to the special needs of unmarried abortion-seekers, young people experiencing symptoms of infection or first-time pregnant women. Limitations are evident in the design of the Reproductive and Child Health-II programme - notably insufficient attention to the heterogeneity of young people and their unmet contraceptive needs, and the different services and delivery modes appropriate for young males and females, and the married and unmarried 
in particular. Involving youth in adapting programmes — designing, implementing, monitoring and evaluating — is essential.

At the same time, this review highlights the huge gaps in knowledge that remain. In many instances, the available evidence is derived from small-scale studies that may not be generalisable to young people at large. Studies have not uniformly explored the context and needs of different groups of young people so the evidence is uneven - sometimes focused on girls, other times on boys; sometimes on the married, other times the unmarried, and among them the better educated. What is available, moreover, tends to be more focused on establishing levels of risk behaviours than exploring the actions that protect sexual and reproductive health and promote informed decisionmaking among them. Hence much of the discussion in this review on actions that protect remains in the realm of informed speculation, relying on a sparse and unrepresentative evidence base.

To make informed policy decisions, more social science and operations research is required on the situation and needs of different groups of adolescents. Equally, we need to better understand whether and why their sexual and reproductive health needs remain unmet, why informed choice continues to elude them and how services should be structured to overcome the social, cultural and economic constraints they face.

- Explore premarital sexual behaviour, the ways in which sexual partnerships are formed, and the meanings that females and males attribute to relationships

Questions that need attention include: What is the nature and duration of different types of partnerships? Do females and males have different perceptions or expectations of relationships? How do females and males perceive sexual responsibility or "appropriate" behaviour within relationships? How do expectations of a relationship influence decisions to practise contraception or safe sex? And to what extent, and by whom, are choices exercised regarding sexual behaviour and the avoidance of disease and unwanted pregnancy? Given increasing HIV among youth, it is critical that research explores the context of risky early sexual encounters and the obstacles youth face in practising safer sex.

\section{- Investigate the sexual and reproductive health needs of married adolescent girls}

Findings confirm that for the majority of sexually active girls, sex is initiated within the context of marriage. Research is needed that explores the manifold needs of married adolescents 
— for information, for skills in articulating and negotiating safe and desired sexual and reproductive health outcomes, and exercising greater autonomy in these matters. Equally, what is needed is operations research that will test the feasibility and acceptability of integrated health and social interventions that would increase young females' reproductive health knowledge and practices, and the ability to act in their own interest.

\section{- Investigate gender roles and life skills that affect young people's health}

Research is needed that explores the ways in which gender roles/expectations and power imbalances in family structures limit or affect life skills among young females and males. More specifically, research is needed to examine ways in which gender double standards and resulting behaviour compromise sexual and reproductive health among females and males with regard to risk behaviours, the timing of marriage or choices regarding parenthood. Of interest in many settings is research that explores the constraints that married adolescent and young women face in accessing information and services, influencing decisions on fertility, contraception, treatment-seeking and sexual relations, and remaining safe from disease, violence and unwanted pregnancy. Research is also needed that identifies the circumstances under which adolescent and young women may be able to exercise greater autonomy in these matters.

\section{- Trace the adverse consequences of unsafe sex among young people: Infection and abortion}

Available evidence suggests that significant minorities of sexually active young males and even females experience infection, and significant minorities of young females experience unintended pregnancy, yet little is known about the pathways they follow in treating the infection or resolving the pregnancy. Community-based studies are needed that explore the kinds of infection that youth experience, as well as the socio-economic and behavioural correlates, including the role of condoms. Research is also needed that explores abortion-seeking behaviour among both unmarried and married adolescent girls, the decision-making process, and factors that underlie delays in seeking termination, resort to untrained providers and higher rates of complication among unmarried young women.

\section{- Explore issues of sexual coercion, force and violence among both young females and males}

Young people, particularly females, are observed to be particularly vulnerable to sexual coercion and violence, that range from an unambiguous use of force to more subtle forms involving economic 
or psychological manipulation. Considerable further research is needed that sensitively explores the levels and patterns of sexual coercion and violence. An issue that needs to be explored is how the presence or threat of violence or coercion limits young people's ability to negotiate safe sex and/or contraception, make reproductive choices, and more generally influence their own reproductive and sexual health.

\section{- Investigate young people's perceptions of "youth-friendly" health services}

Research is needed that explores the use of sexual and reproductive health services by youth and the socio-cultural and programme-related constraints they face in doing so. Available information suggests that few services in fact exist that cater to young people's special health and information needs. Likewise, there are few opportunities for adolescents to seek information or counselling on sexual and reproductive matters. It is critical that research documents young people's own perceptions and priorities with regard to appropriate and acceptable delivery mechanisms for sexual and reproductive health services.

\section{- Investigate the determinants of positive outcomes}

Much of our research has tended to focus on risk behaviours and their determinants. Yet findings have pointed to a number of actions that protect. There is a need for in-depth studies to substantiate or provide greater insight into these protective pathways, and to provide a stronger evidence base on protective actions and strategies for different groups of young people across the country.

\section{- Test the effectiveness and feasibility of programmes for young people}

There are an increasing number of programmes for youth intended to raise awareness, build selfefficacy or provide friendly services. However, these models remain poorly researched and little is known about their feasibility, acceptability, effectiveness and replicability. Research is needed that provides evidence-based directions for future programming.

Cutting across all these recommendations is the reality that young people in India make the transition to adulthood in a rapidly changing social environment. The forces of globalisation on the one hand, and the revolution in the media and information technology on the other hand, have led to a questioning of traditional norms and behaviours. Growing fundamentalism threatens to strengthen traditional gender norms and power imbalances, and may also influence the way young 
people perceive gender roles and behaviours. Research is needed that helps us better understand how contextual influences impact young people, and how they can make the transition to safe sexual lives in a new and changing context. Programmes are required that respond to this changing reality, and that recognise the multidimensionality of young people's lives and concerns. Securing informed health choices for young people entails changes in multiple sectors: the family, society, and health and educational systems. It requires a rethinking of what programmes offer, who programmes are directed to and how programmes are delivered. It also requires an acceptance of changing sexual norms, and the provision of an environment that will support young people to make healthy and informed choices. This paper provides strong support for investment in adolescents - health-promoting practices and negotiation and communication skills developed in adolescence will have far reaching effects on their health and lives as adults. 


\section{References}

Abraham, L. 2001. "Redrawing the lakshman rekha: Gender differences and cultural constructions in youth sexuality in urban India," South Asia 24: 133-156.

_ 2003. "Risk behaviour and misperceptions among low-income college students of Mumbai," in Towards Adulthood: Exploring the Sexual and Reproductive Health of Adolescents in South Asia, ed. S. Bott et al. Geneva: World Health Organisation, pp. 73-77.

Abraham, L. and K.A. Kumar. 1999. "Sexual experiences and their correlates among college students in Mumbai city, India," International Family Planning Perspectives 25(3): 139-146.

Awasthi, S. and V.K. Pande. 1998. "Sexual behaviour patterns and knowledge of sexually transmitted diseases in adolescent boys in urban slums of Lucknow," Indian Paediatrics 35(11): 1105-1109.

Awasthi, S., M. Nichter and V.K. Pande. 2000. "Developing an interactive STD prevention programme for youth: Lessons from a north Indian slum," Studies in Family Planning 31(2): 138-150.

Bang, R.A., A.T. Bang, M. Baitule et al. 1989. "High prevalence of gynaecological diseases in rural Indian women," Lancet 8629: 85-88.

Bansal, R.K. 1992. "Sexual behaviour and substance use patterns amongst adolescent truck cleaners and risk of HIV/AIDS," Indian Journal of Maternal and Child Health 3(4): 108-110.

Barua, A. and K. Kurz. 2001. "Reproductive health-seeking by married adolescent girls in Maharashtra, India," Reproductive Health Matters 9(17): 53-62.

Bhattacharyya, N.N. 1980. Indian Puberty Rites. New Delhi: Munshiram Manoharlal.

_. 1996. Ancient Indian Rituals and their Social Content. New Delhi: Manohar.

Bhende, A. 1995. "Evolving a model for AIDS prevention education among underprivileged adolescent girls in urban India," Women and AIDS Research Program Report, Series No. 5. Washington, DC: International Centre for Research on Women.

Bhuiya, I., U. Rob, M.E. Khan et al. 2003. "Reproductive health services for adolescents: Recent experiences from a pilot project in Bangladesh," in Towards Adulthood: Exploring the Sexual and Reproductive Health of Adolescents in South Asia, ed. S. Bott et al. Geneva: World Health Organisation, pp. 203-206. 
Bott, S., S. Jejeebhoy, I. Shah et al. (eds). 2003. Towards Adulthood: Exploring the Sexual and Reproductive Health of Adolescents in South Asia. Geneva: World Health Organisation.

Brown, A., S.J. Jejeebhoy, I. Shah et al. 2001. "Sexual relations among young people in developing countries: Evidence from WHO case studies," Occasional Papers of the Department of Reproductive Health and Research. World Health Organisation, No. 4 (WHO/RHR/01.8).

Chhabra, S., N. Gupte, A. Mehta et al. 1988. "MTP and concurrent contraceptive adoption in rural India," Studies in Family Planning 19(4): 244-247.

Chakrabarti, V. 2003. "Population education in formal and non-formal sectors in India," in Towards Adulthood: Exploring the Sexual and Reproductive Health of Adolescents in South Asia, ed. S. Bott et al. Geneva: World Health Organisation, pp. 165-167.

Damayanthi, K. 2003. Presentation on Sharing of AP Experience on AIDS Prevention Education Programme (APEP). Hyderabad: APSACS.

Ganatra, B. 2000. "Abortion research in India: What we know, and what we need to know," in Women's Reproductive Health in India, ed. R. Ramasubban and S.J. Jejeebhoy. Jaipur: Rawat Publications, pp. 186-235.

Ganatra, B. and S. Hirve. 2002. "Induced abortions among adolescent women in rural Maharashtra," Reproductive Health Matters 10(19): 76-85.

George, A. and S. Jaswal.1995. "Understanding sexuality: Ethnographic study of poor women in Bombay," Women and AIDS Program Research Report Series No. 12. Washington, D.C.: International Centre for Research on Women.

Goparaju, L. 1993. "Unplanned, unsafe: Male students' sexual behaviour," Paper presented at the Workshop on Sexual Aspects of AIDS/STD Prevention in India, Mumbai, 23-27 November.

Godinho, D., F. Dias-Saxena, G. Divan et al. 2002. Sangath Biennial Report, 2000-2002. Porvorim, Goa: Sangath Society for Child Development and Family Guidance.

Haberland, N., L. McGrory and K.G. Santhya. 2001. "First time parents project, Supplemental diagnostic report." Vadodara, unpublished.

Indian Market Research Bureau (IMRB). 1993. "For better or for worse," Femina 8 July: 6-21.

International Institute for Population Sciences (IIPS) and ORC Macro. 2000. National Family Health Survey (NFHS-2) 1998-99: India. Mumbai: IIPS.

—_. 2000. National Family Health Survey (NFHS-2), India, 1998-99: Andhra Pradesh. Mumbai: IIPS. 
—. 2001. National Family Health Survey (NFHS-2), India, 1998-99: Bihar. Mumbai: IIPS.

—. 2001. National Family Health Survey (NFHS-2), India. 1998-99: Gujarat. Mumbai: IIPS.

—. 2001. National Family Health Survey (NFHS-2), India. 1998-99: Haryana. Mumbai: IIPS.

__—_. 2001. National Family Health Survey (NFHS-2), India. 1998-99: Karnataka. Mumbai: IIPS.

—. 2001. National Family Health Survey (NFHS-2), India, 1998-99: Kerala. Mumbai: IIPS.

—_. 2001. National Family Health Survey (NFHS-2), India. 1998-99: Madhya Pradesh. Mumbai: IIPS.

___ 2001. National Family Health Survey (NFHS-2), India. 1998-99. Maharashtra. Mumbai: IIPS.

—. 2001. National Family Health Survey (NFHS-2), India, 1998-99: Orissa. Mumbai: IIPS.

—. 2001. National Family Health Survey (NFHS-2), India. 1998-99: Punjab. Mumbai: IIPS.

_-_ 2001. National Family Health Survey (NFHS-2), India. 1998-99: Rajasthan. Mumbai: IIPS.

___ 2001. National Family Health Survey (NFHS-2), India, 1998-99: Tamil Nadu. Mumbai: IIPS.

___. 2001. National Family Health Survey (NFHS-2), India, 1998-99: Uttar Pradesh. Mumbai: IIPS.

___ 2001. National Family Health Survey (NFHS-2), India. 1998-99: West Bengal. Mumbai: IIPS.

—. 2002. National Family Health Survey (NFHS-2), India. 1998-99: Delhi. Mumbai: IIPS.

—. 2002. National Family Health Survey (NFHS-2), India. 1998-99: Goa. Mumbai: IIPS.

—. 2002. National Family Health Survey (NFHS-2), India, 1998-99: Himachal Pradesh. Mumbai: IIPS.

—. 2002. National Family Health Survey (NFHS-2), India. 1998-99: Jammu \& Kashmir. Mumbai: IIPS.

- 2002. National Family Health Survey (NFHS-2), India. 1998-99: Northeastern States: Mumbai: IIPS. 
International Labour Organisation (ILO). 1998. Yearbook of Labour Statistics 1998. Geneva: International Labour Organisation.

Jejeebhoy, S. 2000. "Adolescent sexual and reproductive behaviour: A review of the evidence from India," in Women's Reproductive Health in India, ed. R. Ramasubban and S. Jejeebhoy. Jaipur: Rawat Publications, pp. 40-101.

Jejeebhoy, S. and S.S. Halli. 2003. "Marriage patterns in rural India: Influence of socio-cultural context," Unpublished.

Joseph, A., J. Prasad and S. Abraham. 2003. "Gynaecological problems among young married women in Tamil Nadu, India," in Towards Adulthood: Exploring the Sexual and Reproductive Health of Adolescents in South Asia, ed. S. Bott et al. Geneva: World Health Organisation, pp. $138-141$.

Joseph, G.A., S. Bhattacharji, A. Joseph et al. 1997. "General and reproductive health of adolescent girls in rural South India," Indian Pediatrics 34(3): 242-245.

Kaur, U., S.P. Sahni, P. Bembery et al. 1996. "Sexual behaviour, drug use and Hepatitis B infection in Chandigarh students," National Medical Journal of India 9(4): 156-159.

Khan, M.E., J.W. Townsend, R. Sinha et al. 1997. "Sexual violence within marriage: A case study of rural Uttar Pradesh," presented at the Annual Meeting of the American Public Health Association, Indianapolis.

Krishna, U.R. 1995. "The status of women and safe motherhood," Journal of the Indian Medical Association 93(2): 34-35.

Kulkarni, S. 2003. "The reproductive health status of married adolescents as assessed by NFHS-2, India," in Towards Adulthood: Exploring the Sexual and Reproductive Health of Adolescents in South Asia, ed. S. Bott et al. Geneva: World Health Organisation, pp. 55-58.

Levitt-Dayal, M., R. Motihar, S. Kanani et al. 2003. "Adolescent girls in India choose a better future: An impact assessment of an educational programme," in Towards Adulthood: Exploring the Sexual and Reproductive Health of Adolescents in South Asia, ed. S. Bott et al. Geneva: World Health Organisation, pp. 187-189.

Masilamani, R. 2003. "Building a supportive environment for adolescent reproductive health programmes: Essential programme components," in Towards Adulthood: Exploring the Sexual and Reproductive Health of Adolescents in South Asia, ed. S. Bott et al. Geneva: World Health Organisation, pp. 156-158. 
Mehra, S., R. Savithri and L. Coutinho. 2002a. "Gender double standards and power imbalances: Adolescent partnerships in Delhi, India," paper presented at the Asia-Pacific Social Science and Medicine Conference, Kunming, China, October.

_ 2002b. "Sexual behaviour among unmarried adolescents in Delhi, India: Opportunities despite parental controls," paper presented at the IUSSP Regional Population Conference, Bangkok, June.

Mehta, R. 2003. "Establishing adolescent health services in a general health facility," in Towards Adulthood: Exploring the Sexual and Reproductive Health of Adolescents in South Asia, ed. S. Bott et al. Geneva: World Health Organisation, pp. 213-215.

Ministry of Health and Family Welfare (MOHFW). 2000. National Population Policy 2000. New Delhi: Government of India.

- 2003. RCH II and Family Planning: Programme Implementation Plan (PIP). New Delhi: Department of Family Welfare, Ministry of Health and Family Welfare (draft).

Narayan, K.A., D.K. Srinivas, P.J. Pelto et al. 2001. "Puberty rituals, reproductive knowledge and health of adolescent schoolgirls in South India," Asia-Pacific Population Journal 16(2): 225-238.

National AIDS Control Organisation (NACO) and UNICEF. 2002. Knowledge, Attitudes and Practices of Young Adults (15-24 years). New Delhi: NACO and UNICEF.

Pachauri, S. and A. Jamshedji. 1983. "Risks of teenage pregnancy," Journal of Obstetrics and Gynaecology 33(3): 477-482.

Pachauri, S. and K.G. Santhya. 2002. "Socio-demographic and reproductive health profile of adolescents in India: A review," Demography India 31(2).

— 2003. "Contraceptive behaviours of adolescents in Asia: Issues and challenges," in Towards Adulthood: Exploring the Sexual and Reproductive Health of Adolescents in South Asia, ed. S. Bott et al. Geneva: World Health Organisation, pp. 108-113.

Patel, V. and G. Andrew. 2001. "Gender, sexual abuse and risk behaviours in adolescents: A crosssectional survey in schools in Goa," National Medical Journal of India 14(5): 263-267.

Pelto, P.J., A. Joshi and R. Verma. 2000. Development of Sexuality and Sexual Behaviour among Indian Males: Implications for Reproductive Health Programmes. New Delhi: Population Council. 
Planning Commission. 2001. Report of the Working Group on Adolescents for the Tenth Five Year Plan (2002-2007). New Delhi: Government of India.

Poonkhum, Y. 2003. "Providing adolescent-friendly reproductive health services: The Thai experience," in Towards Adulthood: Exploring the Sexual and Reproductive Health of Adolescents in South Asia, ed. S. Bott et al. Geneva: World Health Organisation, pp. 210-212.

Population Reference Bureau (PRB). 2000. The World's Youth 2000. Washington, DC: Population Reference Bureau, Measure Communication.

Ramakrishna, J., M. Karott and R.S. Murthy. 2003. "Experiences of sexual coorcion among street boys in Bangalore, India," in Towards Adulthood: Exploring the Sexual and Reproductive Health of Adolescents in South Asia, ed. S. Bott et al. Geneva: World Health Organisation, pp. 95-98.

Santhya, K.G. and S.J. Jejeebhoy. 2003. "Sexual and reproductive health needs of married adolescent girls," Economic and Political Weekly 38(41): 4370-4377.

Santhya, K.G., L. McGrory and N. Haberland. 2001. "First time parents project, Supplemental diagnostic report, Kolkata," unpublished.

Savara, M. and C.R. Sridhar. 1993. "Sexual behaviour patterns amongst men and women in Maharashtra: Results of survey," Paper presented at the Workshop on Sexual Aspects of AIDS/ STD Prevention in India, Mumbai, 23-27 November.

—. 1994. "Sexual behaviour amongst different occupational groups in Maharashtra, India, and the implications for AIDS education," Indian Journal of Social Work 55(4): 617-632.

Sebastian, M., D. Huntington, W. Clark et al. 2002a. Project Update 2: Baseline Survey Results: Integrating Adolescent Livelihood Activities within a Reproductive Health Program for Urban Slum Dwellers in India. New Delhi: Population Council.

Sebastian, M., D. Huntington, B. Mensch et al. 2002b. Project Update 3: Midline Survey Results: Integrating Adolescent Livelihood Activities within a Reproductive Health Program for Urban Slum Dwellers in India. New Delhi: Population Council.

Sebastian, M.P., D. Huntington, B. Mensch et al. 2003. "FRONTIERS final report: Integrating adolescent livelihood activities within a reproductive health program for urban slum dwellers in India," unpublished. 
Sehgal, V.N., A.K. Sharma and S.N. Bhattacharya. 1992. "K.A.B.P. study on AIDS among school boys," abstract published in the 2nd International Congress on AIDS in Asia and the Pacific Abstracts. Randwick, Australia, AIDS Society of Asia and the Pacific.

Senderowitz, J. 1999. Making Reproductive Health Services Youth Friendly. Washington, DC: Pathfinder International, FOCUS on Young Adults.

Sharma, V. and A. Sharma. 1995. "Safe sex: A mirage in a desert? The sexual behaviour of adolescent boys in Gujarat, India," Paper presented at the 6th International Congress on Adolescent Health, Vancouver, 20-25 March.

Singh, E. 2003. "Adolescent reproductive health in South Asia: Key issues and priorities for action," in Towards Adulthood: Exploring the Sexual and Reproductive Health of Adolescents in South Asia, ed. S. Bott et al. Geneva: World Health Organisation, pp. 48-52.

Singh, S. 1998. "Adolescent childbearing in developing countries: A global review," Studies in Family Planning 29(2): 117-163.

Singh, M.M., R. Devi and S.S. Gupta. 1999. "Awareness and health seeking behaviour of rural adolescent school girls on menstrual and reproductive health problems," Indian Journal of Medical Sciences 53(9): 439-443.

Sodhi, G. and M. Verma. 2003. "Sexual coercion among unmarried adolescents of an urban slum in India," in Towards Adulthood: Exploring the Sexual and Reproductive Health of Adolescents in South Asia, ed. S. Bott et al. Geneva: World Health Organisation, pp. 91-94.

_ (forthcoming). "Seeking gratification: A study of sexual behaviour patterns of adolescents in an urban slum," in Reproductive Health in India: New Evidence, ed. M. Koenig et al.

Solapurkar, M. and R. Sangam. 1985. "Has the MTP Act in India proved beneficial?" Journal of Family Welfare 31(3): 46-52.

Subba Rao. 2003. "School AIDS Education Programme," AP Education Department presentation. United Nations. 2001. World Population Prospects: The 2000 Revision. Volume II: The Sex and Age Distribution of the World Population. New York: United Nations.

UNESCO. 2000. "Cultural settings affect adolescent needs," Adolescence Education Newsletter 3(2): 6.

UNICEF, UNAIDS, WHO. 2002. Young People and HIV/AIDS: Opportunity in Crisis. Geneva: United Nations Children's Fund, Joint United Nations Programme on HIV/AIDS, World Health Organisation. 
Vietnam Educational Scientific Institute. 1999. "Needs assessment study on adolescent reproductive health and behaviours, Bihar," Population Education Bulletin 8(1): 19.

Watsa, M.C. 1993. "Premarital sexual behaviour of urban educated youth in India," paper presented at the Workshop on Sexual Aspects of AIDS/STD Prevention in India, Mumbai, 23-27 November. 


\section{Appendix Table 1}

Age at marriage among adolescents, India, 1998-99

\begin{tabular}{|c|c|c|c|}
\hline \multirow[t]{2}{*}{ States } & \multicolumn{2}{|c|}{$\begin{array}{l}\text { Percentage of population aged } 15-19 \\
\text { who have ever been married }\end{array}$} & \multirow{2}{*}{$\begin{array}{l}\text { Percentage of } \\
\text { married women } \\
\text { aged } 20-24 \\
\text { who were married } \\
\text { by exact age } 15 \\
\end{array}$} \\
\hline & Male & Female & \\
\hline India & 6.3 & 33.6 & 23.5 \\
\hline Delhi & 1.7 & 9.5 & 4.5 \\
\hline Haryana & 4.3 & 23.3 & 8.8 \\
\hline Himachal Pradesh & 0.5 & 5.1 & 0.7 \\
\hline Jammu \& Kashmir & 1.1 & 8.5 & 6.0 \\
\hline Punjab & 1.1 & 8.1 & 1.2 \\
\hline Rajasthan & 20.8 & 48.5 & 35.7 \\
\hline Madhya Pradesh & 11.2 & 42.0 & 38.6 \\
\hline Uttar Pradesh & 10.3 & 39.9 & 36.0 \\
\hline Bihar & 10.3 & 46.0 & 40.4 \\
\hline Orissa & 2.1 & 17.4 & 9.8 \\
\hline West Bengal & 2.6 & 36.9 & 17.2 \\
\hline Arunachal Pradesh & 2.8 & 15.0 & 7.7 \\
\hline Assam & 2.6 & 24.1 & 9.6 \\
\hline Manipur & 1.1 & 8.6 & 1.2 \\
\hline Meghalaya & 0.8 & 14.3 & 4.2 \\
\hline Mizoram & 1.4 & 8.4 & 0.6 \\
\hline Nagaland & 3.1 & 13.4 & 3.6 \\
\hline Sikkim & 2.9 & 16.3 & 4.5 \\
\hline Tripura & 1.0 & 22.9 & 10.4 \\
\hline Goa & 1.1 & 6.2 & 3.6 \\
\hline Gujarat & 5.8 & 26.5 & 12.4 \\
\hline Maharashtra & 2.6 & 29.6 & 22.5 \\
\hline Andhra Pradesh & 3.5 & 44.9 & 30.6 \\
\hline Karnataka & 2.0 & 31.6 & 20.5 \\
\hline Kerala & 0.1 & 14.1 & 3.1 \\
\hline Tamil Nadu & 0.7 & 23.7 & 3.7 \\
\hline
\end{tabular}

Source: NFHS-2, India (IIPS and ORC Macro 2000), Tables 2.3 (cols 1 and 2) and 3.4 (col. 3). For state-wise data, see IIPS and ORC Macro 2000-02; for the north-eastern states, Tables 2.2 and 3.3, respectively; for other states, Tables 2.3 and 3.3, respectively. 


\section{Appendix Table 2}

Casual sex experience among adolescents aged 15-19, India, 2001

\begin{tabular}{|c|c|c|c|c|c|c|c|c|}
\hline \multirow[t]{3}{*}{ States } & \multicolumn{2}{|c|}{$\begin{array}{l}\text { Percentage of } \\
\text { respondents } \\
\text { reporting casual } \\
\text { sex in a one- } \\
\text { year recall } \\
\text { period* }\end{array}$} & \multicolumn{2}{|c|}{$\begin{array}{l}\text { Percentage of } \\
\text { respondents } \\
\text { reporting } \\
\text { consistent } \\
\text { condom use in } \\
\text { casual sex } \\
\text { partnerships in } \\
\text { a one-year recall } \\
\text { period }^{+}\end{array}$} & \multicolumn{2}{|c|}{$\begin{array}{l}\text { Percentage of } \\
\text { respondents } \\
\text { reporting } \\
\text { casual sex in a } \\
\text { one-year recall } \\
\text { period* }\end{array}$} & \multicolumn{2}{|c|}{$\begin{array}{l}\text { Percentage of } \\
\text { respondents } \\
\text { reporting } \\
\text { consistent } \\
\text { condom use in } \\
\text { casual sex } \\
\text { partnerships in a } \\
\text { one-year recall }_{\text {period }^{+}}\end{array}$} \\
\hline & \multicolumn{4}{|c|}{ Rural } & \multicolumn{4}{|c|}{ Urban } \\
\hline & Male & Female & Male & Female & Male & Female & Male & Female \\
\hline India & 10.1 & 2.2 & 24.7 & 23.9 & 8.0 & 2.4 & 36.2 & 28.4 \\
\hline Delhi & 11.8 & 0.0 & 20.0 & NA & 3.2 & 0.0 & 0.0 & NA \\
\hline Haryana & 9.1 & 0.7 & 13.3 & 100.0 & 6.7 & 0.7 & 22.2 & 0.0 \\
\hline Himachal Pradesh & 2.6 & 0.0 & 33.3 & NA & 3.5 & 0.0 & 20.0 & NA \\
\hline Jammu \& Kashmir & 12.1 & 3.0 & 34.8 & 25.0 & 6.8 & 0.8 & 37.5 & 0.0 \\
\hline Punjab & 8.4 & 0.0 & 54.5 & NA & 9.3 & 1.2 & 50.0 & 0.0 \\
\hline Rajasthan & 3.5 & 0.6 & 0.0 & 0.0 & 3.6 & 0.0 & 80.0 & 0.0 \\
\hline Madhya Pradesh & 27.9 & 0.8 & 14.8 & 0.0 & 12.1 & 1.2 & 26.7 & 100.0 \\
\hline Uttar Pradesh & 8.7 & 0.0 & 14.3 & NA & 4.7 & 0.0 & 14.3 & NA \\
\hline Bihar & 13.9 & 11.1 & 10.0 & 0.0 & 20.4 & 10.9 & 22.2 & 0.0 \\
\hline Orissa & 4.6 & 0.7 & 0.0 & 0.0 & 4.5 & 0.0 & 50.0 & NA \\
\hline West Bengal & 2.9 & 0.8 & 0.0 & 0.0 & 2.5 & 0.9 & 33.3 & 100.0 \\
\hline Arunachal Pradesh & 23.5 & 4.8 & 62.5 & 0.0 & 17.4 & 5.6 & 50.0 & 100.0 \\
\hline Assam & 13.0 & 0.9 & 12.5 & 0.0 & 1.5 & 1.7 & 50.0 & 50.0 \\
\hline Manipur & 6.6 & 0.0 & 0.0 & NA & 0.7 & 0.0 & 100.0 & NA \\
\hline Meghalaya & 8.4 & 0.0 & 0.0 & NA & 12.5 & 0.0 & 0.0 & NA \\
\hline Mizoram & 23.5 & 2.4 & 12.5 & 0.0 & 16.3 & 3.2 & 42.9 & 50.0 \\
\hline Nagaland & 5.7 & 9.5 & 0.0 & 50.0 & 7.4 & 0.0 & 0.0 & NA \\
\hline Sikkim & 17.1 & 0.0 & 38.5 & NA & 11.9 & 0.7 & 46.7 & 0.0 \\
\hline Tripura & 9.1 & 3.8 & 100.0 & 100.0 & 5.7 & 3.4 & 100.0 & 0.0 \\
\hline Goa & 4.5 & 0.0 & 100.0 & NA & 9.0 & 0.0 & 75.0 & NA \\
\hline Gujarat & 27.0 & 2.2 & 20.0 & 0.0 & 20.1 & 2.2 & 46.4 & 0.0 \\
\hline Maharashtra & 3.2 & 3.7 & 0.0 & 25.0 & 6.0 & 7.7 & 57.1 & 50.0 \\
\hline Andhra Pradesh & 18.2 & 15.3 & 22.7 & 19.0 & 24.5 & 12.8 & 28.6 & 17.6 \\
\hline Karnataka & 0.0 & 1.2 & - & 0.0 & 2.3 & 1.6 & 33.3 & 0.0 \\
\hline Kerala & 9.8 & 6.0 & 41.7 & 85.7 & 3.5 & 6.9 & 50.0 & 33.3 \\
\hline Tamil Nadu & 0.0 & 0.0 & NA & NA & 3.8 & 0.0 & 20.0 & NA \\
\hline
\end{tabular}

Source: NACO and UNICEF 2002. * Table $5.22{ }^{+}$Table 5.24

$N A=$ not available 


\section{Appendix Table 3}

\section{Contraceptive use and unmet need for contraception among married adolescents aged 15-19}

\begin{tabular}{|c|c|c|c|}
\hline States & $\begin{array}{l}\text { \% married } \\
\text { adolescents currently } \\
\text { practising } \\
\text { contraception }\end{array}$ & $\begin{array}{l}\% \text { married } \\
\text { adolescents currently } \\
\text { practising } \\
\text { modern contraception }\end{array}$ & $\begin{array}{l}\text { \% married } \\
\text { adolescents expressing } \\
\text { an unmet need for } \\
\text { contraception }\end{array}$ \\
\hline India & 8.0 & 4.7 & 27.1 \\
\hline Delhi & 16.3 & 9.8 & 29.1 \\
\hline Haryana & 9.2 & 3.8 & 7.7 \\
\hline Himachal Pradesh & 6.0 & 4.0 & 18.7 \\
\hline Jammu \& Kashmir & 7.4 & 2.4 & 42.8 \\
\hline Punjab & 16.5 & 7.7 & 6.3 \\
\hline Rajasthan & 4.1 & 2.9 & 32.3 \\
\hline Madhya Pradesh & 5.3 & 4.3 & 26.9 \\
\hline Uttar Pradesh & 5.4 & 2.5 & 29.3 \\
\hline Bihar & 2.4 & 1.2 & 31.4 \\
\hline Orissa & 4.7 & 3.4 & 21.8 \\
\hline West Bengal & 33.1 & 11.1 & 28.9 \\
\hline Arunachal Pradesh & 9.5 & 9.5 & 37.0 \\
\hline Assam & 13.4 & 5.3 & 20.3 \\
\hline Manipur & $(20.3)$ & $(9.1)$ & $(31.2)$ \\
\hline Meghalaya & (8.7) & (3.0) & $(40.9)$ \\
\hline Mizoram & $(14.9)$ & $(14.9)$ & $(43.9)$ \\
\hline Nagaland & 0 & 0 & $(41.7)$ \\
\hline Sikkim & 17.6 & 4.0 & 37.5 \\
\hline Tripura & 18.5 & 14.5 & 42.9 \\
\hline Goa & NA & NA & NA \\
\hline Gujarat & 9.6 & 6.5 & 18.1 \\
\hline Maharashtra & 6.5 & 6.2 & 31.2 \\
\hline Andhra Pradesh & 7.4 & 7.4 & 20.8 \\
\hline Karnataka & 5.6 & 5.1 & 27.7 \\
\hline Kerala & 7.0 & 3.3 & 30.5 \\
\hline Tamil Nadu & 5.6 & 5.0 & 20.4 \\
\hline
\end{tabular}

Source: NFHS-2, India (IIPS and ORC Macro 2000), Tables 5.4 (cols 1 and 2) and 5.23 (col. 3). For state-wise data, see IIPS and ORC Macro 2000-02; for the north-eastern states, Tables 5.3 and 5.18, respectively; for other states, Tables 5.3 and 5.15 , respectively.

$N A=$ not available.

() Indicates small sample size. 


\section{Appendix Table 4}

Unsafe pregnancy outcomes among adolescents: Risk factors and neonatal mortality rates

\begin{tabular}{|c|c|c|c|c|}
\hline \multirow[t]{2}{*}{ States } & \multirow{2}{*}{$\begin{array}{l}\text { Median age at } \\
\text { first birth } \\
\text { Ages 25-29 }\end{array}$} & \multirow{2}{*}{$\begin{array}{l}\text { \% moderately } \\
\text { or severely } \\
\text { anaemic }\end{array}$} & \multicolumn{2}{|c|}{$\begin{array}{l}\text { Neonatal mortality rate per } \\
1,000 \text { births* }\end{array}$} \\
\hline & & & Ages 15-19 & Ages 20-29 \\
\hline India & 19.6 & 19.8 & 63.1 & 40.7 \\
\hline Delhi & 21.5 & 11.6 & $(51.4)$ & 21.2 \\
\hline Haryana & 20.2 & 22.9 & 52.8 & 28.7 \\
\hline Himachal Pradesh & 21.3 & 12.8 & $(38.6)$ & 24.8 \\
\hline Jammu \& Kashmir & 21.8 & 19.6 & 49.4 & 36.4 \\
\hline Punjab & 21.5 & 15.9 & $(44.5)$ & 33.6 \\
\hline Rajasthan & 19.5 & 18.4 & 65.1 & 50.2 \\
\hline Madhya Pradesh & 18.4 & 18.5 & 84.2 & 51.7 \\
\hline Uttar Pradesh & 18.9 & 17.7 & 85.4 & 52.2 \\
\hline Bihar & 18.9 & 20.4 & 65.9 & 42.8 \\
\hline Orissa & 20.0 & 24.8 & 80.1 & 46.3 \\
\hline West Bengal & 19.5 & 15.9 & 42.8 & 26.4 \\
\hline Arunachal Pradesh & 19.9 & 19.6 & $(21.2)$ & 22.3 \\
\hline Assam & 20.4 & 29.0 & 40.8 & 31.4 \\
\hline Manipur & 24.8 & $(14.6)$ & NA & 17.9 \\
\hline Meghalaya & 20.7 & $(22.8)$ & $(71.6)$ & 46.0 \\
\hline Mizoram & 23.3 & $(13.4)$ & NA & 22.2 \\
\hline Nagaland & 21.4 & (16.3) & NA & 28.7 \\
\hline Sikkim & 21.8 & 24.8 & NA & NA \\
\hline Tripura & 20.3 & 12.2 & $(50.3)$ & 39.4 \\
\hline Goa & 26.3 & 5.8 & NA & NA \\
\hline Gujarat & 20.4 & 24.3 & 62.2 & 37.0 \\
\hline Maharashtra & 19.2 & 21.1 & 51.1 & 31.9 \\
\hline Andhra Pradesh & 18.3 & 19.7 & 52.1 & 42.9 \\
\hline Karnataka & 19.3 & 23.9 & 55.2 & 36.6 \\
\hline Kerala & 22.5 & 2.4 & $(16.0)$ & 12.5 \\
\hline Tamil Nadu & 21.5 & 22.6 & 43.2 & 33.8 \\
\hline
\end{tabular}

Source: NFHS-2, India (IIPS and ORC Macro 2000), Tables 4.13 (col. 1), 7.6 (col. 2) and 6.5 (cols 3-4). For state-wise data, see IIPS and ORC Macro 2000-02; for the north-eastern states, Tables 4.8, 7.5 and 6.3, respectively; for other states, Tables 4.9, 7.4 and 6.4, respectively.

* Neonatal mortality rate refers to the 10-year period preceding the survey.

Data for Goa cover the age group 30-34 years (col. 1) and 20-24 years (col. 2).

() Indicates small sample size.

$N A=$ not available 


\section{Appendix Table 5}

In-depth awareness of HIV-related issues: \% adolescents aged 15-19 aware of important methods of HIV prevention and correctly aware of three common misconceptions on transmission of HIV/AIDS

\begin{tabular}{|c|c|c|c|c|c|c|c|c|}
\hline \multirow[t]{3}{*}{ States } & \multicolumn{4}{|c|}{$\begin{array}{l}\text { Respondents aware of important } \\
\text { methods of HIV prevention } \\
\text { (consistent condom use and } \\
\text { sex with a faithful uninfected partner) }\end{array}$} & \multicolumn{4}{|c|}{$\begin{array}{l}\text { Respondents correctly aware of } \\
\text { three common misconceptions on } \\
\text { transmission of HIV/AIDS } \\
\text { (mosquito bites and sharing } \\
\text { a meal with an infected person do not } \\
\text { transmit HIV/AIDS, and that a healthy } \\
\text { looking person can transmit HIV/AIDS) }\end{array}$} \\
\hline & \multicolumn{2}{|c|}{ Urban } & \multicolumn{2}{|c|}{ Rural } & \multicolumn{2}{|c|}{ Urban } & \multicolumn{2}{|c|}{ Rural } \\
\hline & Male & Female & Male & Female & Male & Female & Male & Female \\
\hline India & 60.0 & 55.6 & 54.1 & 44.5 & 30.3 & 31.8 & 21.8 & 20.2 \\
\hline Delhi & 69.1 & 68.6 & 53.5 & 60.2 & 22.8 & 20.3 & 18.9 & 20.3 \\
\hline Haryana & 78.5 & 68.8 & 73.3 & 51.4 & 31.8 & 30.5 & 26.7 & 15.7 \\
\hline Himachal Pradesh & 66.7 & 65.6 & 62.9 & 60.7 & 31.9 & 64.1 & 25.9 & 47.1 \\
\hline Jammu \& Kashmir & 77.8 & 77.3 & 73.2 & 64.9 & 42.7 & 63.0 & 22.1 & 17.6 \\
\hline Punjab & 75.0 & 65.1 & 78.6 & 62.4 & 42.6 & 39.5 & 35.1 & 34.6 \\
\hline Rajasthan & 61.6 & 57.3 & 52.1 & 32.9 & 30.4 & 32.2 & 21.5 & 19.9 \\
\hline Madhya Pradesh & 45.2 & 59.3 & 41.0 & 29.3 & 13.7 & 19.8 & 17.0 & 9.8 \\
\hline Uttar Pradesh & 54.7 & 48.1 & 38.9 & 19.6 & 19.6 & 12.2 & 8.9 & 6.5 \\
\hline Bihar & 57.9 & 50.0 & 37.5 & 15.9 & 22.7 & 14.1 & 8.3 & 7.9 \\
\hline Orissa & 56.7 & 35.8 & 37.4 & 17.0 & 29.1 & 23.6 & 11.4 & 7.5 \\
\hline West Bengal & 24.4 & 26.4 & 27.2 & 16.5 & 28.6 & 20.9 & 11.0 & 9.4 \\
\hline Arunachal Pradesh & 60.9 & 44.4 & 41.2 & 26.2 & 17.4 & 44.4 & 11.8 & 42.9 \\
\hline Assam & 27.7 & 19.3 & 21.9 & 16.8 & 16.1 & 15.8 & 5.7 & 5.6 \\
\hline Manipur & 78.9 & 79.2 & 69.7 & 53.2 & 67.7 & 55.0 & 34.2 & 26.9 \\
\hline Meghalaya & 62.5 & 33.3 & 23.9 & 28.2 & 27.1 & 18.2 & 4.2 & 12.8 \\
\hline Mizoram & 86.0 & 66.1 & 73.5 & 57.1 & 79.1 & 72.6 & 85.3 & 80.9 \\
\hline Nagaland & 25.9 & 53.0 & 40.0 & 14.3 & 25.9 & 23.5 & 17.1 & 9.5 \\
\hline Sikkim & 73.0 & 67.4 & 55.3 & 45.7 & 34.9 & 25.7 & 19.1 & 17.2 \\
\hline Tripura & 20.0 & 20.7 & 22.7 & 3.8 & 14.3 & 17.2 & 4.5 & 15.4 \\
\hline Goa & 66.4 & 60.7 & 64.3 & 71.5 & 26.1 & 44.4 & 22.3 & 24.4 \\
\hline Gujarat & 78.4 & 40.7 & 64.9 & 20.1 & 21.6 & 20.9 & 18.0 & 4.3 \\
\hline Maharashtra & 36.2 & 49.3 & 60.2 & 63.3 & 36.2 & 49.8 & 39.8 & 28.0 \\
\hline Andhra Pradesh & 59.4 & 50.4 & 52.1 & 64.2 & 32.9 & 30.1 & 29.7 & 32.8 \\
\hline Karnataka & 61.7 & 59.4 & 54.6 & 55.6 & 9.4 & 7.8 & 9.2 & 4.9 \\
\hline Kerala & 60.5 & 61.1 & 53.7 & 62.1 & 44.7 & 37.4 & 48.0 & 44.8 \\
\hline Tamil Nadu & 60.0 & 65.7 & 57.7 & 45.6 & 33.1 & 12.7 & 25.0 & 5.4 \\
\hline
\end{tabular}

Source: NACO and UNICEF 2002, Tables 5.11 and 5.12. 


\section{Appendix Table 6}

\section{Pregnancy-related care among adolescents aged 15-19}

\begin{tabular}{|c|c|c|c|c|}
\hline States & $\begin{array}{l}\% \text { receiving no } \\
\text { antenatal } \\
\text { check-up }\end{array}$ & $\begin{array}{l}\text { \% women who } \\
\text { delivered at } \\
\text { health facility/ } \\
\text { institution }\end{array}$ & $\begin{array}{l}\% \text { attended by } \\
\text { trained health } \\
\text { personnel }\end{array}$ & $\begin{array}{l}\text { \% receiving } \\
\text { postpartum } \\
\text { check-up* }\end{array}$ \\
\hline India & 31.7 & 31.8 & 41.6 & 18.1 \\
\hline Delhi & 11.6 & 43.8 & 50.3 & NA \\
\hline Haryana & 42.7 & 18.0 & 38.0 & 12.4 \\
\hline Himachal Pradesh & 17.3 & 31.4 & 42.1 & 20.0 \\
\hline Jammu \& Kashmir & 16.9 & 34.3 & 43.6 & 19.5 \\
\hline Punjab & 29.5 & 48.9 & 71.2 & NA \\
\hline Rajasthan & 52.3 & 23.5 & 40.7 & 4.9 \\
\hline Madhya Pradesh & 38.7 & 17.9 & 28.7 & 10.5 \\
\hline Uttar Pradesh & 60.9 & 17.2 & 23.8 & 8.4 \\
\hline Bihar & 57.6 & 15.2 & 26.3 & 10.0 \\
\hline Orissa & 23.0 & 19.0 & 27.4 & 17.9 \\
\hline West Bengal & 6.9 & 41.2 & 45.3 & 31.1 \\
\hline Arunachal Pradesh & 28.7 & 38.1 & 39.2 & NA \\
\hline Assam & 36.9 & 11.9 & 15.7 & 27.1 \\
\hline Manipur & 12.6 & 27.4 & 47.8 & NA \\
\hline Meghalaya & 40.3 & 15.4 & 18.0 & NA \\
\hline Mizoram & 12.3 & 54.9 & 62.3 & NA \\
\hline Nagaland & 48.2 & 11.4 & 30.7 & NA \\
\hline Sikkim & 31.3 & 37.6 & 41.2 & NA \\
\hline Tripura & 17.8 & 49.3 & 54.4 & \\
\hline Goa & NA & NA & NA & NA \\
\hline Gujarat & 18.0 & 39.9 & 46.9 & 9.5 \\
\hline Maharashtra & 9.3 & 44.1 & 52.4 & 27.8 \\
\hline Andhra Pradesh & 5.6 & 47.6 & 66.0 & 44.6 \\
\hline Karnataka & 17.4 & 43.9 & 54.5 & 35.4 \\
\hline Kerala & 0.0 & 89.3 & 90.8 & NA \\
\hline Tamil Nadu & 0.9 & 75.6 & 80.6 & 46.3 \\
\hline
\end{tabular}

Source: NFHS-2, India (IIPS and ORC Macro 2000), Tables 8.2 (col. 1), 8.8 (col. 2), 8.9 (col. $3,8.11$ (col. 4). For statewise data, see IIPS and ORC Macro 2000-02; for the north-eastern states, Tables 8.2 (col. 1), 8.8 (col. 2), 8.10 (col. 3); for other states, Tables 8.2 (col. 1), 8.7 (col. 2), 8.8 (col. 3), 8.10, (col. 4). For Kerala and Tamil Nadu, Tables 8.2 (col. 1), 8.6 (col. 2), 8.7 (col. 3), 8.10 (col. 4).

* The denominator is non-institutional births during the three years preceding the survey. $N A=$ not available. 
